A. Subba Rao*, Seela Sainath, P.Rajendra, and G.Ramu

\title{
Mathematical Modelling of Hydromagnetic Casson non-Newtonian Nanofluid Convection Slip Flow from an Isothermal Sphere
}

https://doi.org/10.1515/nleng-2018-0016

Received January 17, 2018; revised April 17, 2018; accepted June 7, 2018. namic heat, momentum and mass (species) transfer in external boundary layer flow of Casson nanofluid from an isothermal sphere surface with convective condition under an applied magnetic field is studied theoretically. The effects of Brownian motion and thermophoresis are incorporated in the model in the presence of both heat and nanoparticle mass transfer convective conditions. The governing partial differential equations (PDEs) are transformed into highly nonlinear, coupled, multi-degree nonsimilar partial differential equations consisting of the momentum, energy and concentration equations via appropriate non-similarity transformations. These transformed conservation equations are solved subject to appropriate boundary conditions with a second order accurate finite difference method of the implicit type. The influences of the emerging parameters i.e. magnetic parameter $(M)$, Buoyancy ratio parameter $(N)$, Casson fluid parameter $(\beta)$, Brownian motion parameter $(\mathrm{Nb})$ and thermophoresis parameter $(N t)$, Lewis number (Le), Prandtl number $(P r)$ and thermal slip $\left(S_{T}\right)$ on velocity, temperature and nano-particle concentration distributions is illustrated graphically and interpreted at length.

Increasing viscoplastic (Casson) parameter decelerates the flow and also decreases thermal and nano-particle concentration. Increasing Brownian motion accelerates the flow and enhances temperatures whereas it reduces nanoparticle concentration boundary layer thickness. Increasing thermophoretic parameter increasing momentum (hydrodynamic) boundary layer thickness and nanoparticle boundary layer thickness whereas it reduces thermal boundary layer thickness. Increasing magnetohydrodynamic body force parameter decelerates the flow whereas it enhances temperature and nano-particle (species) concentrations. The study is relevant to enrobing processes for electric-conductive nano-materials, of potential use in aerospace and other industries.
Keywords: Magnetic nanofluid; Species diffusion; Steady flow; Nanoparticles; Casson viscoplastic model; Kellerbox numerical method; Heat transfer

\section{Introduction}

The word "nanotechnology" was probably used for the first time by the Japanese scientist Norio Taniguchi in 1974. K. Eric Drexler is credited with initial theoretical work in the field of nanotechnology. The term nanotechnology was used by Drexler in his 1986 book "Engines of creation: The coming era of nanotechnology". Drexler's idea of nanotechnology is referred to as molecular nanotechnology [1]. Earlier the great theoretical physicist Richard Feynman predicted nanotechnology in 1959. In the 1980s and 1990s new nano-materials were discovered and nanofluids emerged as a result of the experiments intended to increase the thermal conductivity of liquids. The birth of nanofluids is attributed to the revolutionary idea of adding solid particles into fluids to increase the thermal conductivity. This innovative idea was put forth by the Scottish physicist J.C. Maxwell as early as 1873.

Nanofluids have evolved into a very exciting and rich frontier in modern nano-technology. The excitement can be attributed to the robustness of the concept of nanofluid and the plethora of different applications of this technology [2]. The properties of nanofluid need a lot of fine tuning, many seemingly contradicting studies need clarity and validation. Nanofluid have potential applications in micro-electronics, fuel cells, rocket propulsion, and environmental de-toxification, spray coating of aircraft wings,

\footnotetext{
*Corresponding Author: A. Subba Rao, Department of Mathematics, Madanapalle Institute of Technology and Science, Madanapalle517325, India, E-mail: asrsvu@gmail.com Seela Sainath, IV B.Tech student, Department of Mechanical Engineering, Madanapalle Institute of Technology \& Science, Madanapalle, Madanapalle-517325, India

P.Rajendra, G.Ramu, Department of Mathematics, Madanapalle Institute of Technology and Science, Madanapalle-517325, India
} 
pharmaceutical suspensions, medical sprays etc. These applications of nanofluid are largely attributable to the enhanced thermal conductivity and Brownian motion dynamics which can be exploited to immense benefit. Nanomaterial work efficiently as new energy materials since they incorporate suspended particles with size as the same as or smaller than the size of de Broglie wave [3].

Recently, nanofluid are used in several engineering and industrial applications, including, geothermal reservoir, thermal insulation, floor heating, cancer therapy, nuclear reactor cooling and process industries. The word "nanofluid" was first presented by Choi and Eastman [4], and concluded that heat transfer characteristics in common fluids can be increased via suspended nanoparticles. Later on, Buongiorno [5] explored that out of seven slip mechanisms, only Brownian diffusion and thermophoresis are important slip mechanism in nanofluid. Further, based on his findings, he proposed a model for mass, momentum and heat transport in nanofluid, known as Buongiorno model. Several investigators utilized this model whilst considered different types of base fluids. Kuznetsov and Nield [6] studied the buoyancy effects in viscous nanofluid induced due to vertical plate. They predicted that heat transfer declined with increase in Brownian motion and thermophoresis parameters. Abdul-Kahar et al. [7] examined the effects of chemical reaction and thermal radiation on boundary layer flow of Newtonian nanofluid over stretching surface.

The study of MHD boundary layer flow of nanofluid over wedge has gained considerable attention in the last few years due to its increasing numbers of scientific, engineering and industrial applications such as MHD pumps, accelerators, generators, high temperature plasmas, cooling of nuclear reactors, biological transportation and drug delivery. The applied magnetic field is usually used in controlling momentum and heat transfer in the boundary layer flow of different fluids Turkyilmazoglu [8].

Due to its several practical applications, the boundary layer flow of non-Newtonian fluids has gained an immense interest in the recent years. It is well-known that non-Newtonian fluids are usually effective in the manufacturing process of coated sheets, foods, plastic polymers and blood Shit et al. [9]. The complexity of these fluids offers a special challenge to engineers, physicist and mathematicians. It is also a common belief that the behavior of theses fluids cannot be demonstrated by a single constitutive relation Shehzad et al. [10]. For this purpose, several models have been proposed of which Casson fluid model Casson [11] is one of them. Casson fluid model is classified as non-Newtonian fluid based on its solid and liquid interaction behavior. Casson fluid possesses shear thinning property, it behaves like solid if the applied shear stress is lesser than yield stress, whereas if applied shear stress exceeds from yield stress, it starts move Abdul Hakeem et al. [12]. Moreover, Casson nanofluid has useful applications in polymer processes, manufacturing of plastic or rubber sheets, chemical process equipment, food industries, advanced cooling systems, etc.

The analytical solution of Casson nanofluid due to stretching surface in the presence of convective boundary condition was presented by Nadeem et al. [13]. On the other hand, (Imtiaz et al. [14] studied the mixed convection flow of Casson nanofluid generated by stretching cylinder under the influence of convective boundary condition. They noticed that momentum boundary layer thickness dropped with increment in Casson parameters. Iqbal et al. [15] and Mahmood et al. [16] studied theoretically the boundary layer flow of micro polar Casson fluid due to stretching surface in the presence and absence of magnetic field. The numerical solutions were obtained via Kellerbox and Runge-Kutta-Fehelberg schemes, respectively.

The above studies considered the nanofluid to be electrically non-conducting. However new developments in magnetic nanofluid have emerged in recent years which require magnetohydrodynamics to simulate the response of nanofluid to applied magnetic fields. Representative systems in which such fluids arise include energy devices [17] and medical engineering $[18,19]$. A number of researchers have simulated various types of multi-physical hydrodynamics problems of magnetic nanofluid in different configurations, using a diverse range of numerical methods. Qing et al. [20] studied entropy generation in magnetized reactive radiative Casson nanofluid over a porous stretching/shrinking surface with successive linearization and Chebyshev spectral collocation methods.The fuselages of aircrafts and hulls of underwater vehicles can also be modeled as cylindrical shells, and the control of vibrations and sound radiation is important. In the low frequency region, active control shows promise for the reduction of vibrations and radiated sound. Very recently Janicki et al. [21] studied that realization of the system for the active control of boundary conditions during the dynamic thermal characterization of electronic components. Gao et al. [22] were the first authors to introduce passive control of an impinging jet for heat transfer enhancement. The authors found that the addition of triangular tabs at the pipe exit leads to a heat transfer enhancement with an excess of 25 $\%$. Popiel and Boguslawski [23] confirmed that the configuration of the nozzle exit is the most important factor affecting the heat and mass transfer which occur in the neighborhood of the stagnation point. In spite of these first very significant observations, there are only a few stud- 
ies dedicated to heat and mass transfer enhancement using jet passive control. Passive control techniques [24, 25], which are commonly used to improve jet self-induction and mixing processes. Soomro et al. [26] demonstrate Passive control of nanoparticle due to convective heat transfer over a stretching surface. This recent studies (passive boundary condition) provides one of the motivations for the present research. Nadeem et al. [27, 28] presented Optimal Homotopy analysis solutions of micropolar flow in rotating parallel plates. Nadeem et al. [29] explored the convective heating effects of MHD oblique flow of a Walter's B fluid model. Rana et al. studied heat transference in viscoplastic boundary layer flow over a stretching sheet with convective conditions [30, 31]. Mehmood et al. [32] investigated the problem of oblique stagnation point flow using Jeffery nanofluid as a rheological fluid model. Mehmood et al. [33] utilized hematite as a heat enhancing agent to investigate the non-aligned stagnation flow and heat transfer of an Ethylene-Glycol and water based nanofluid towards an extending surface. They observed that Ethylenebased nanofluids have higher local heat flux as compared with water-based nanofluids. Mehmood et al. [34] studied mixed convection and thermal radiation on non-aligned Casson fluid over a stretching surface. Governing equations of the problem were solved by shooting method coupled with Runge-Kutta- Fehlberg integration technique. Nadeem et al. [35] deliberated steady stagnation point flow of Jeffery fluid towards a stretching surface. Tabassum et al. [36] explored the influence of temperature dependent viscosity on Oblique flow of micro polar nanofluid. Mahmood et al. [37] analyzed the micro rotation effects on mixed convection flow induced by a stretching sheet. They carried out numerical investigation by employing Runge-Kutta Fehlberg scheme coupled with shooting technique. M.R. Eid and K.L. Mahny [57], study the heat transfer effects in Sisko nanofluid in the presence of porous medium over a nonlinearly stretching sheet with heat generation/absorption effects. Eid, M.R. and S.R. Mishra [58], analyzed the non-Newtonian fluid flow over a permeable non-linear stretching vertical surface with heat and mass fluxes. A.M. Rashad [59] studied the Impact of thermal radiation on MHD slip flow of a Ferro fluid over a nonisothermal wedge.

The above studies were generally confined to internal transport. However external boundary layer convection flows also find applications in many technological systems including enrobing polymer coating processes, heat exchanger design, solar collector architecture etc. Prasad et al. [38] studied two-dimensional nanofluid boundary layer flow from a spherical geometry embedded in porous media with a finite difference scheme. Subba Rao et al. [39] investigated computationally the heat transfer in magnetized non-Newtonian fluid boundary layer flow from an isothermal sphere with Soret and Dufour effects. Makanda et al. [40] analyzed the radiative heat flux effect on hydromagnetic dissipative Casson slip fluid flow from a horizontal circular cylinder in porous media. Beg et al. [41] derived both homotopy and Adomian decomposition numerical solutions for transient stagnation-point heat and mass transfer from a rotating sphere.

The present work, motivated by applications in enrobing dynamics of magnetic nanomaterial's [42], examines theoretically and computationally the steady-state transport phenomena in magnetohydrodynamic Casson nanofluid flow from an isothermal sphere with thermal slip. Mathematical modelling is developed to derive the equations of continuity, momentum, energy and species conservation, based on the Buongiorno nanofluid model [6]. The partial differential boundary layer equations are then transformed into a system of dimensionless non-linear coupled differential boundary layer equations, which is solved with the robust second order accurate Keller box implicit finite difference method. The present work extends significantly earlier simulations of Hussain et al. [43] (who consider an exponentially stretching surface) to the case of a horizontal circular cylinder with thermal slip condition. An extensive parametric analysis of the influence of a number of parameters (Brownian motion, thermophoresis, Casson non-Newtonian, thermal slip, stream wise coordinate) on thermo-diffusive characteristics is conducted. The simulations are also relevant to calendaring in pseudo-plastic materials fabrication [44].

\section{Magnetohydrodynamic Nanofluid Slip Model}

We examine magneto-hydrodynamic (MHD) steady buoyancy-driven convection heat transfer flow of Casson nanofluid from an isothermal sphere in the presence of thermal slip. Figure 1 shows the flow model and associated coordinate system. The nanofluid fluid is taken to be incompressible and a homogenous dilute solution. Magnetic field of strength, $B_{o}$, is applied normally to the flow.

The $\mathrm{x}$-coordinate is measured along the circumference of the isothermal sphere from the lowest point and the $\mathrm{y}$-coordinate is measured normal to the surface, and $\mathrm{r}$ is the radial distance from symmetric axis to the surface $r=$ $a \sin \left(\frac{x}{a}\right)$ and ' $a$ ' denoting the radius of the sphere. The gravitational acceleration, $\mathbf{g}$ acts downwards. Both the 


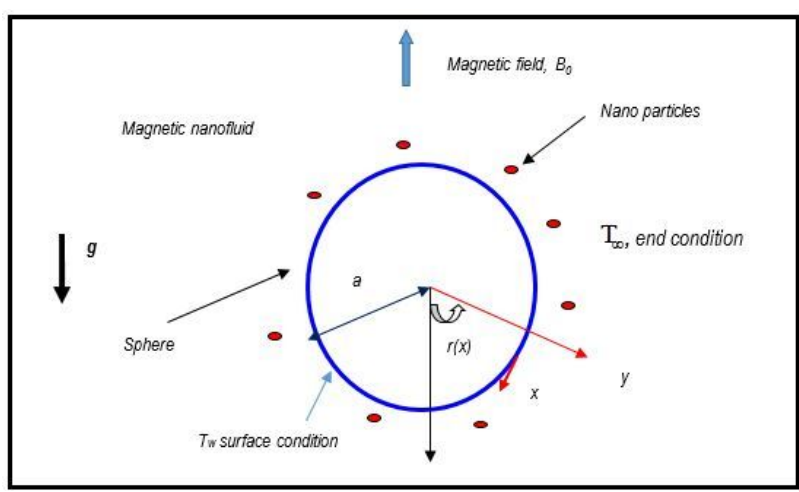

Fig. 1: Physical model and coordinate system

isothermal sphere and the fluid are maintained initially at the same temperature. Instantaneously they are raised to a temperature $T_{w}>T_{\infty}$ i.e. the ambient temperature of the fluid which remains unchanged. The appropriate constitutive equations for the Casson non-Newtonian model are:

$$
\tau_{i j}=\left\{\begin{array}{c}
2\left(\mu_{B}+\frac{p_{y}}{\sqrt{2 \pi}}\right) e_{i j}, \pi \geq \pi_{c} \\
2\left(\mu_{B}+\frac{p_{y}}{\sqrt{2 \pi_{c}}}\right) e_{i j}, \pi<\pi_{c}
\end{array}\right.
$$

in which $\pi=e_{i j} e_{i j}$ and $e_{i j}$ is the (i,j) ${ }^{t h}$ component of deformation rate, $\pi$ denotes the product of the component of deformation rate with itself, $\pi_{c}$ shows a critical value of this product based on the non-Newtonian model, $\mu_{B}$ the plastic dynamic viscosity of non-Newtonian fluid and $p_{y}$ the yield stress of fluid. The Casson model, although relatively simple, is a robust viscoplastic model and describes accurately the shear stress-strain behavior of certain industrial polymers in which flow is not possible prior to the attainment of a critical shear stress. Unlike the Bingham viscoplastic model which has a linear shear rate, the Casson model has a non-linear shear rate. Casson fluid theory was originally propounded to simulate shear thinning (viscosity is reduced with greater shear rates) liquids containing rod-like solids and is equally popular in analysing inks, emulsions, food stuffs (chocolate melts), certain gels and paints [45]. More recently it has been embraced in advanced polymeric flow processing [46]. Incorporating the Casson terms and applying the Buongiorno nanofluid model, the governing conservation equations, in primitive form, for the regime under investigation i.e. mass continuity, momentum, energy and species, can be written as follows:

$$
\frac{\partial u}{\partial x}+\frac{\partial v}{\partial y}=0
$$

$$
\begin{gathered}
u \frac{\partial u}{\partial x}+v \frac{\partial u}{\partial y}=v\left(1+\frac{1}{\beta}\right) \frac{\partial^{2} u}{\partial y^{2}}+g \Omega\left(T-T_{\infty}\right) \sin \left(\frac{x}{a}\right) \\
+g \Omega^{\star}\left(C-C_{\infty}\right) \sin \left(\frac{x}{a}\right)-\frac{\sigma B_{0}^{2}}{\rho} u \\
u \frac{\partial T}{\partial x}+v \frac{\partial T}{\partial y}=\alpha \frac{\partial^{2} T}{\partial y^{2}}+\tau\left(D_{B} \frac{\partial C}{\partial y} \frac{\partial T}{\partial y}+\frac{D_{T}}{T_{\infty}}\left(\frac{\partial T}{\partial y}\right)^{2}\right) \\
u \frac{\partial C}{\partial x}+v \frac{\partial C}{\partial y}=D_{B} \frac{\partial^{2} C}{\partial y^{2}}+\frac{D_{T}}{T_{\infty}} \frac{\partial^{2} T}{\partial y^{2}}
\end{gathered}
$$

The boundary conditions imposed at the sphere surface and in the free stream are:

$$
\begin{aligned}
& \text { At } y=0, u=0, v=0,-k \frac{\partial T}{\partial y}=h_{1}\left(T_{f}-T\right), \quad C=C_{w} \\
& \text { As } y \rightarrow \infty, u \rightarrow 0, v \rightarrow 0, T \rightarrow T_{\infty}, C \rightarrow C_{\infty}
\end{aligned}
$$

Here $u$ and $v$ are the velocity components in the $x$ and $y$ - directions respectively, $v$ - the kinematic viscosity of the electrically-conducting nanofluid, $\beta$ - is the non-Newtonian Casson parameter respectively, $\rho_{f}$ is the density of fluid, $\sigma$ is the electrical conductivity of the nanofluid, $\alpha$ - the thermal diffusivity of the nanofluid, $T$ the temperature, respectively. Furthermore $\tau=\frac{(\rho c)_{p}}{(\rho c)_{f}}$ is the ratio of nanoparticle heat capacity and the base fluid heat capacity, $D_{B}$ is the Brownian diffusion coefficient; $D_{T}$ is the thermophoretic diffusion coefficient; $k$ is the thermal conductivity of nanofluid; $T_{w}$ and $C_{\infty}$ are the ambient fluid temperature and concentration, $C_{p}$ is the specific heat capacity; $\Omega$ and $\Omega^{\star}$ are the coefficients of thermal expansion and concentration expansion, respectively.

The stream function $\psi$ is defined by the CauchyRiemann equations, $u=\frac{\partial \psi}{\partial y}$ and $v=-\frac{\partial \psi}{\partial x}$, and therefore, the continuity equation is automatically satisfied. In order to write the governing equations and the boundary conditions in dimensionless form, the following nondimensional quantities are introduced [39].

$$
\begin{gathered}
\xi=\frac{x}{a}, \quad \eta=\frac{y}{a} G r^{1 / 4}, \quad f(\xi, \eta)=\frac{\psi}{v \xi G r^{1 / 4}}, \\
\theta(\xi, \eta)=\frac{T-T_{\infty}}{T_{w}-T_{\infty}}, \quad \phi(\xi, \eta)=\frac{C-C_{\infty}}{C_{w}-C_{\infty}}
\end{gathered}
$$

The transformed boundary layer equations for momentum, energy and concentration emerge as:

$$
\begin{aligned}
& \left(1+\frac{1}{\beta}\right) f^{\prime \prime \prime}+f f^{\prime \prime}-f^{\prime 2}+\frac{\sin \xi}{\xi}(\theta+N \phi)-M f^{\prime} \\
& =\xi\left(f^{\prime} \frac{\partial f^{\prime}}{\partial \xi}-f^{\prime \prime} \frac{\partial f}{\partial \xi}\right) \\
& \frac{\theta^{\prime \prime}}{\operatorname{Pr}}+f \theta^{\prime}+N_{b} \phi^{\prime} \theta^{\prime}+N_{t} \theta^{\prime 2}=\xi\left(f^{\prime} \frac{\partial \theta}{\partial \xi}-\theta^{\prime} \frac{\partial f}{\partial \xi}\right) \\
& \frac{\phi^{\prime \prime}}{L e}+f \phi^{\prime}+\frac{1}{L e} \frac{N_{b}}{N_{t}} \theta^{\prime \prime}=\xi\left(f^{\prime} \frac{\partial \phi}{\partial \xi}-\phi^{\prime} \frac{\partial f}{\partial \xi}\right)
\end{aligned}
$$


The corresponding transformed dimensionless boundary conditions are:

At $\eta=0, \quad f=0, \quad f^{\prime}=1, \quad \theta^{\prime}=-S_{T}(1-\theta(0)), \quad \phi=1$

$$
\text { As } \eta \rightarrow \infty, \quad f^{\prime} \rightarrow 0, \quad \theta \rightarrow 0, \quad \phi \rightarrow 0
$$

where $\operatorname{Pr}=y / \alpha$ is Prandtl number; $M=\frac{\sigma B_{0}^{2} a^{2}}{y \rho G r^{1 / 2}}$ is the magnetic parameter; $\mathrm{Gr}$ is a Grashof buoyancy number; $L e=$ $\frac{y}{D_{B}}$ is the Lewis number; $N_{t}=\frac{(\rho c)_{p} D_{T}\left(T_{W}-T_{\infty}\right)}{(\rho c)_{f} y T_{\infty}}$ is the thermophoresis parameter; $N_{b}=\frac{(\rho c)_{p} D_{B}\left(C_{w}-C_{\infty}\right)}{(\rho c)_{f} y}$ is the Brownian parameter; $N=\frac{\Omega^{*}\left(C_{w}-C_{\infty}\right)}{\Omega\left(T_{w}-T_{\infty}\right)}$ is the concentration to thermal buoyancy ratio parameter, $S_{T}=\left(\frac{h_{1}}{k}\right) a G r^{-1 / 4}$ is the thermal slip parameter. All other parameters are defined in the nomenclature. The skin-friction coefficient (sphere surface shear stress function), the local Nusselt number (heat transfer rate) and Sherwood number (mass transfer rate) can be defined using the transformations described above with the following expressions:

$$
\begin{gathered}
\frac{1}{2} G r^{-3 / 4} C_{f}=\left(1+\frac{1}{\beta}\right) \xi f^{\prime \prime}(\xi, 0) \\
G r^{-1 / 4 N u}=-\theta^{\prime}(\xi, 0) \\
G r^{-1 / 4 S h}=-\phi^{\prime}(\xi, 0)
\end{gathered}
$$

\section{Numerical Solution With Keller Box Implict Method}

The strongly coupled, nonlinear conservation equations do not admit analytical (closed-form) solutions. An elegant, implicit difference finite difference numerical method developed by Keller [47] is therefore adopted to solve the general flow model defined by eqns. (8)-(10) with boundary conditions (11). This method is especially appropriate for boundary layer flow equations which are parabolic in nature. It remains one of the most widely applied computational methods in viscous fluid dynamics. Recent problems which have used Keller's method include radiative magnetic forced convection flow [48], stretching sheet hydromagnetic flow [49], magnetohydrodynamic Falkner-Skan "wedge" flows [50], magneto-rheological flow from an extending cylinder [51], Hall magneto-gas dynamic generator slip flows [52] and radiative-convective Casson slip boundary layer flows [53]. Keller's method provides unconditional stability and rapid convergence for strongly non-linear flows. It involves four key stages, summarized below.
1) Reduction of the $N^{\text {th }}$ order partial differential equation system to $N$ first order equations

2) Finite difference discretization of reduced equations

3) Quasilinearization of non-linear Keller algebraic equations

4) Block-tridiagonal elimination of linearized Keller algebraic equations

\section{Stage 1: Reduction of the $\boldsymbol{N}^{\text {th }}$ order partial differential equation system to $\boldsymbol{N}$ first order equations}

Equations (8)-(10) and (11) subject to the boundary conditions are first written as a system of first-order equations. For this purpose, we reset eqns. (6)-(7) as a set of simultaneous equations by introducing the new variables.

$$
\begin{aligned}
& f^{\prime}=u \\
& u^{\prime}=v \\
& \theta=s \\
& s^{\prime}=t \\
& g^{\prime}=p
\end{aligned}
$$

$$
\begin{gathered}
\left(1+\frac{1}{\beta}\right) v^{\prime}+(1+\xi \cot \xi) f v-u^{2}+\frac{\sin \xi}{\xi}(s+N g)-M f^{\prime} \\
=\xi\left(u \frac{\partial u}{\partial \xi}-v \frac{\partial f}{\partial \xi}\right) \\
\frac{t^{\prime}}{\operatorname{Pr}}+(1+\xi \cot \xi) f t+N_{b} \phi^{\prime} t+N_{t} t^{2} \\
=\xi\left(u \frac{\partial s}{\partial \xi}-t \frac{\partial f}{\partial \xi}\right) \\
\frac{p^{\prime}}{L e}+(1+\xi \cot \xi) f p+\frac{1}{L e} \frac{N_{b}}{N_{t}} t^{\prime}=\xi\left(u \frac{\partial g}{\partial \xi}-p \frac{\partial f}{\partial \xi}\right)
\end{gathered}
$$

Where primes denote differentiation with respect to $\eta$. In terms of the dependent variables, the boundary conditions become

$$
\begin{array}{r}
\text { At } \eta=0: \quad u=0, \quad f=0, \quad s=1, \quad g=1 \\
\text { At } \eta \rightarrow \infty: u \rightarrow 0, \quad v \rightarrow 0, \quad s \rightarrow 0, \quad g \rightarrow 0
\end{array}
$$

Stage 2: Finite difference discretization of reduced boundary layer equations 


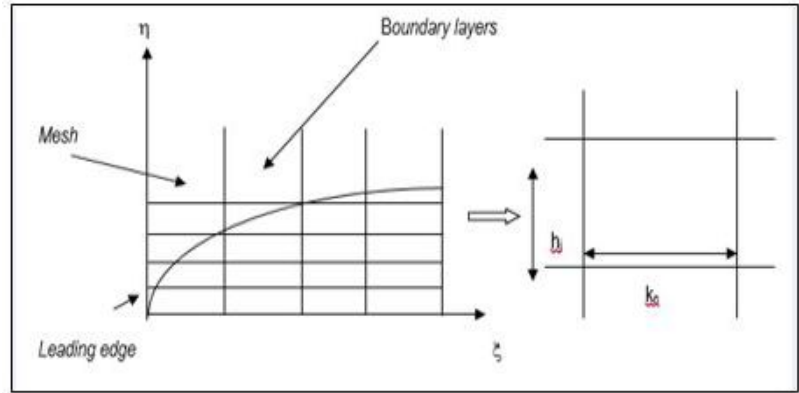

Fig. 2: Keller Box element and boundary layer mesh

A two-dimensional computational grid (mesh) is imposed on the $\xi-\eta$ plane as sketched in Fig. 2. The stepping process is defined by:

$$
\begin{gathered}
\eta_{0}=0, \quad \eta_{j}=\eta_{j-1}+h_{j}, \\
j=1,2, \ldots, J, \quad \eta_{J} \equiv \eta_{\infty} \\
\xi^{0}=0, \quad \xi^{n}=\xi^{n-1}+k_{n}, \quad n=1,2, \ldots, N
\end{gathered}
$$

Where $k_{n}$ and $h_{j}$ denote the step distances in the $\xi$ (stream wise) and $\eta$ (span wise) directions respectively.

If $g_{j}^{n}$ denotes the value of any variable at $\left(\eta_{j}, \xi^{n}\right)$, then the variables and derivatives of eqns. (15)-(22) at $\left(\eta_{j-1 / 2}, \xi^{n-1 / 2}\right)$ are replaced by:

$$
\begin{gathered}
g_{j-1 / 2}^{n-1 / 2}=\frac{1}{4}\left(g_{j}^{n}+g_{j-1}^{n}+g_{j}^{n-1}+g_{j-1}^{n-1}\right), \\
\left(\frac{\partial g}{\partial \eta}\right)_{j-1 / 2}^{n-1 / 2}=\frac{1}{2 h_{j}}\left(g_{j}^{n}-g_{j-1}^{n}+g_{j}^{n-1}-g_{j-1}^{n-1}\right), \\
\left(\frac{\partial g}{\partial \xi}\right)_{j-1 / 2}^{n-1 / 2}=\frac{1}{2 k^{n}}\left(g_{j}^{n}-g_{j-1}^{n}+g_{j}^{n-1}-g_{j-1}^{n-1}\right),
\end{gathered}
$$

The finite-difference approximation of eqns. (15)-(22) for the mid-point $\left(\eta_{j-1 / 2}, \xi^{n}\right)$, below:

$$
\begin{aligned}
& h_{j}^{-1}\left(f_{j}^{n}-f_{j-1}^{n}\right)=u_{j-1 / 2}^{n}, \\
& h_{j}^{-1}\left(u_{j}^{n}-u_{j-1}^{n}\right)=v_{j-1 / 2}^{n}, \\
& h_{j}^{-1}\left(g_{j}^{n}-g_{j-1}^{n}\right)=p_{j-1 / 2}^{n}, \\
& h_{j}^{-1}\left(\theta_{j}^{n}-\theta_{j-1}^{n}\right)=t_{j-1 / 2}^{n},
\end{aligned}
$$

$$
\begin{aligned}
& \left(1+\frac{1}{\beta}\right)\left(v_{j}-v_{j-1}\right)+\frac{(1+\alpha+\xi \cot \xi) h_{j}}{4} \\
& {\left[\left(f_{j}+f_{j-1}\right)\left(v_{j}+v_{j-1}\right)\right]-\frac{(1+\alpha) h_{j}}{4}\left(u_{j}+u_{j-1}\right)^{2}} \\
& +\frac{A h_{j}}{2}\left(s_{j}+s_{j-1}+N\left(g_{j}+g_{j-1}\right)\right)-\frac{M h_{j}}{2}\left(u_{j}+u_{j-1}\right) \\
& -\frac{\alpha h_{j}}{2} f_{j-1 / 2}^{n-1}\left(v_{j}+v_{j-1}\right)+\frac{\alpha h_{j}}{2} v_{j-1 / 2}^{n-1}\left(f_{j}+f_{j-1}\right) \\
& =\left[R_{1}\right]_{j-1 / 2}^{n-1}
\end{aligned}
$$

$$
\begin{aligned}
& \frac{1}{\operatorname{Pr}}\left(t_{j}-t_{j-1}\right)+\frac{(1+\alpha+\xi \cot \xi) h_{j}}{4}\left[\left(f_{j}+f_{j-1}\right)\left(t_{j}+t_{j-1}\right)\right] \\
& -\frac{\alpha h_{j}}{4}\left[\left(u_{j}+u_{j-1}\right)\left(s_{j}+s_{j-1}\right)\right] \\
& +N b \frac{h_{j}}{4}\left[\left(t_{j}+t_{j-1}\right)\left(p_{j}+p_{j-1}\right)\right]+N t \frac{h_{j}}{4}\left(t_{j}+t_{j-1}\right)^{2} \\
& +\frac{\alpha h_{j}}{2} s_{j-1 / 2}^{n-1}\left(u_{j}+u_{j-1}\right)-\frac{\alpha h_{j}}{2} u_{j-1 / 2}^{n-1}\left(s_{j}+s_{j-1}\right) \\
& -\frac{\alpha h_{j}}{2} f_{j-1 / 2}^{n-1}\left(t_{j}+t_{j-1}\right)+\frac{\alpha h_{j}}{2} t_{j-1 / 2}^{n-1}\left(f_{j}+f_{j-1}\right)=\left[R_{2}\right]_{j-1 / 2}^{n-1}
\end{aligned}
$$

$\frac{1}{L e}\left(p_{j}-p_{j-1}\right)+\frac{(1+\alpha+\xi \cot \xi) h_{j}}{4}\left[\left(f_{j}+f_{j-1}\right)\left(p_{j}+p_{j-1}\right)\right]$

$+\frac{B}{L e}\left(t_{j}-t_{j-1}\right)-\frac{\alpha h_{j}}{4}\left[\left(u_{j}+u_{j-1}\right)\left(g_{j}+g_{j-1}\right)\right]$

$+\frac{\alpha h_{j}}{2} s_{j-1 / 2}^{n-1}\left(u_{j}+u_{j-1}\right)-\frac{\alpha h_{j}}{2} u_{j-1 / 2}^{n-1}\left(g_{j}+g_{j-1}\right)$

$-\frac{\alpha h_{j}}{2} f_{j-1 / 2}^{n-1}\left(p_{j}+p_{j-1}\right)+\frac{\alpha h_{j}}{2} p_{j-1 / 2}^{n-1}\left(f_{j}+f_{j-1}\right)=\left[R_{2}\right]_{j-1 / 2}^{n-1}$

Where the following notation applies:

$$
\alpha=\frac{\xi^{n-1 / 2}}{k_{n}}, A=\frac{\sin \left(\xi^{n-1 / 2}\right)}{\xi^{n-1 / 2}}, B=\frac{N t}{N b}
$$

$\left[R_{1}\right]_{j-1 / 2}^{n-1}=-h_{j}\left[\begin{array}{l}\left(1+\frac{1}{\beta}\right)\left(\frac{v_{j}-v_{j-1}}{h_{j}}\right)+(1-\alpha)\left(u_{j-1 / 2}\right)^{2} \\ +(1-\alpha+\xi \cot \xi)\left(f_{j-1 / 2} v_{j-1 / 2}\right) \\ +A\left(s_{j-1 / 2}+N g_{j-1 / 2}\right)-M\left(u_{j-1 / 2}\right)\end{array}\right]$

$\left[R_{2}\right]_{j-1 / 2}^{n-1}$

$$
=-h_{j}\left[\begin{array}{l}
\frac{1}{\operatorname{Pr}}\left(\frac{t_{j}-t_{j-1}}{h_{j}}\right)+(1-\alpha+\xi \cot \xi)\left(f_{j-1 / 2} t_{j-1 / 2}\right) \\
+\alpha\left(u_{j-1 / 2} s_{j-1 / 2}\right)-N b\left(p_{j-1 / 2} t_{j-1 / 2}\right) \\
-N t\left(t_{j-1 / 2}\right)^{2}
\end{array}\right]
$$




$$
\begin{aligned}
& {\left[R_{3}\right]_{j-1 / 2}^{n-1}} \\
& =-h_{j}\left[\begin{array}{l}
\frac{1}{L e}\left(\frac{p_{j}-p_{j-1}}{h_{j}}\right)+(1-\alpha+\xi \cot \xi)\left(f_{j-1 / 2} p_{j-1 / 2}\right) \\
+\frac{B}{L e}\left(\frac{t_{j}-t_{j-1}}{h_{j}}\right)+\alpha\left(u_{j-1 / 2} g_{j-1 / 2}\right)
\end{array}\right]
\end{aligned}
$$

The boundary conditions are

$$
\begin{aligned}
& f_{0}^{n}=u_{0}^{n}=0, \quad \theta_{0}^{n}=1, \quad u_{J}^{n}=0, \quad v_{J}^{n}=0, \\
& \theta_{J}^{n}=0, \quad \varphi_{0}^{n}=1, \quad \varphi_{J}^{n}=0
\end{aligned}
$$

Stage 3: Quasilinearization of non-linear Keller algebraic equations

If we assume $f_{j-1}^{n-1}, u_{j-1}^{n-1}, v_{j-1}^{n-1}, p_{j-1}^{n-1}, s_{j-1}^{n-1}, t_{j-1}^{n-1}$, to be known for

Equations (30) - (36) comprise a system of $6 \mathrm{~J}+6$ equations for the solution of $6 \mathrm{~J}+6$ unknowns $f_{j}^{n}, u_{j}^{n}, v_{j}^{n}, p_{j}^{n}, s_{j}^{n}, t_{j}^{n}, j=0,1,2 \ldots, J$. This non-linear system of algebraic equations is linearized by means of Newton's method as elaborated by Keller [47] and recently this method is used by Subba Rao et al., [54, 55].

\section{Stage 4: Block-tridiagonal elimination of linear Keller} algebraic equations

The linearized version of eqns. (30) - (36) can now be solved by the block-elimination method, since they possess a block-tridiagonal structure since it consists of block matrices. The complete linearized system is formulated as a block matrix system, where each element in the coefficient matrix is a matrix itself. Then, this system is solved using the efficient Keller-box method. The numerical results are affected by the number of mesh points in both directions. After some trials in the $\eta$-direction (radial coordinate) a larger number of mesh points are selected whereas in the $\xi$ direction (tangential coordinate) significantly less mesh points are utilized. $\eta_{\max }$ has been set at 12 and this defines an adequately large value at which the prescribed boundary conditions are satisfied. $\xi_{\max }$ is set at 1.0 for this flow domain. Mesh independence testing is also performed to ensure that the converged solutions are correct. The computer program of the algorithm is executed in MATLAB running on a PC.

\section{Keller Box Method (KBM) Numerical Results and Discussion}

Comprehensive solutions have been obtained with KBM and are presented in Figs. 3 to 11. The numerical problem comprises three dependent thermo-fluid dynamic variables $(f, \theta, \phi)$ and seven multi-physical control parameters, Pr, Le, $\beta, \mathrm{M}, \mathrm{Nb}, \mathrm{Nt}, \mathrm{S}_{T}$,. The influence of stream wise space variable $\xi$ is also investigated. In the present computations, the following default parameters are prescribed (unless otherwise stated): $\operatorname{Pr}=7.0, \mathrm{Le}=5.0, \beta=1.5, \mathrm{M}=0.01$, $\mathrm{Nb}=0.02=\mathrm{Nt}, \mathrm{S}_{T}=1.0, \xi=1.0$.

Figs. 3(a-c) illustrate the effect of the Casson viscoplastic parameter, $\beta$ on velocity $\left(f^{\prime}\right)$, temperature $(\theta)$ and concentration $(\phi)$ profiles. With increasing, $\beta$ values, initially close to the sphere surface, Fig. 3(a) shows that the flow is strongly decelerated. However, further from the surface, the converse response is induced in the flow. This may be related to the necessity for a yield stress to be attained prior to viscous flow initiation in viscoplastic shearthinning nanofluids. Within a short distance of the sphere surface, however a strong acceleration is generated with greater Casson parameter. This serves to decrease momentum boundary layer thickness effectively. The viscoplastic parameter modifies the shear term $\mathrm{f}^{/ /}$in the momentum boundary layer equation (8) with an inverse factor, $1 / \beta$, and effectively assists momentum diffusion for $\beta>1$. This leads to a thinning in the hydrodynamic boundary layer and associated deceleration. The case $\beta=0$ which corresponds to a Newtonian fluid is not considered. An increase in viscoplastic parameter however decreases both temperature and nano-particle concentration magnitudes throughout the boundary layer, although the reduction is relatively weak. Thermal and nanoparticle concentration boundary layer thickness are both suppressed with greater viscoplasticity of the nanofluid.

Figs. 4(a-c) depicts the effect of Prandtl number (Pr) on the velocity $\left(f^{\prime}\right)$, temperature $(\theta)$ and nanoparticle concentration $(\phi)$ distributions with transverse coordinate $(\eta)$. Fig. 4(a) shows that with increasing Prandtl number there is a strong deceleration in the flow. The Prandtl number expresses the ratio of momentum diffusion rate to thermal diffusion rate. When Pr is unity both momentum and heat diffuse at the same rate and the velocity and thermal boundary layer thicknesses are the same. With $\mathrm{Pr}>$ 1 there is a progressive decrease in thermal diffusivity relative to momentum diffusivity and this serves to retard the boundary layer flow. Momentum boundary layer thickness therefore grows with Prandtl number on the surface of the isothermal sphere. It is also noteworthy that the peak velocity which is achieved close to the sphere surface is systematically displaced closer to the surface with greater Prandtl number. The asymptotically smooth profiles of velocity which decays to zero in the free stream, also confirm the imposition of an adequately large infinity boundary condition. Fig. 4(b) indicates that increasing Prandtl number also suppresses temperatures in the boundary layer and therefore reduces thermal boundary layer thickness. Prandtl number is inversely proportional to thermal 


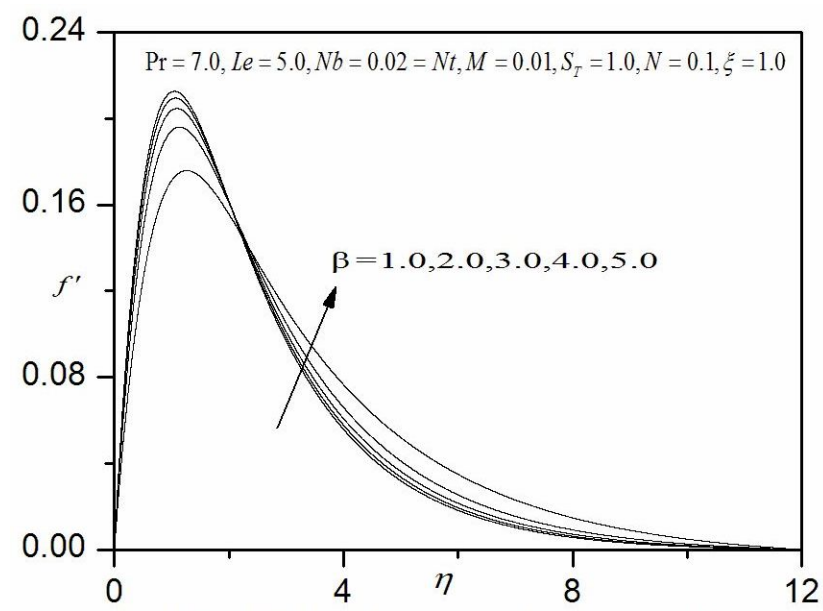

(a)

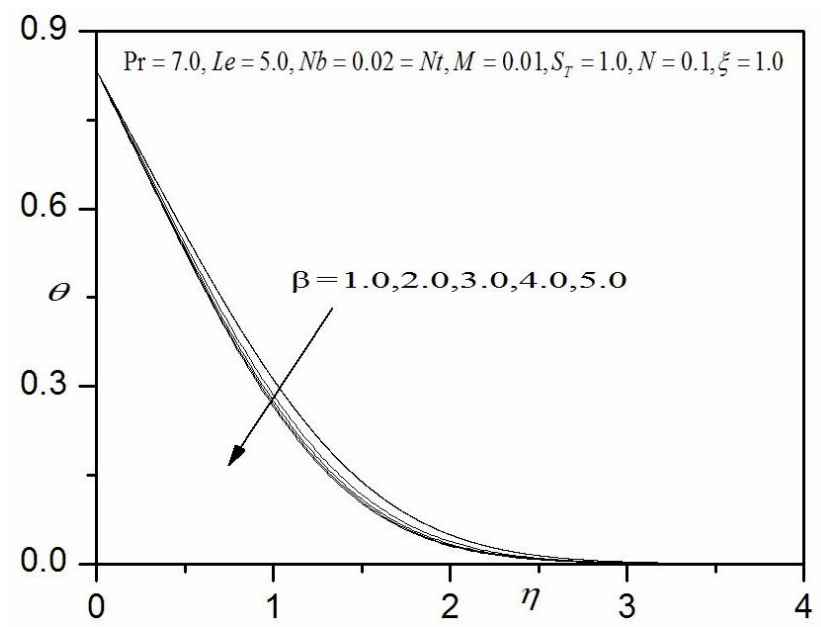

(b)

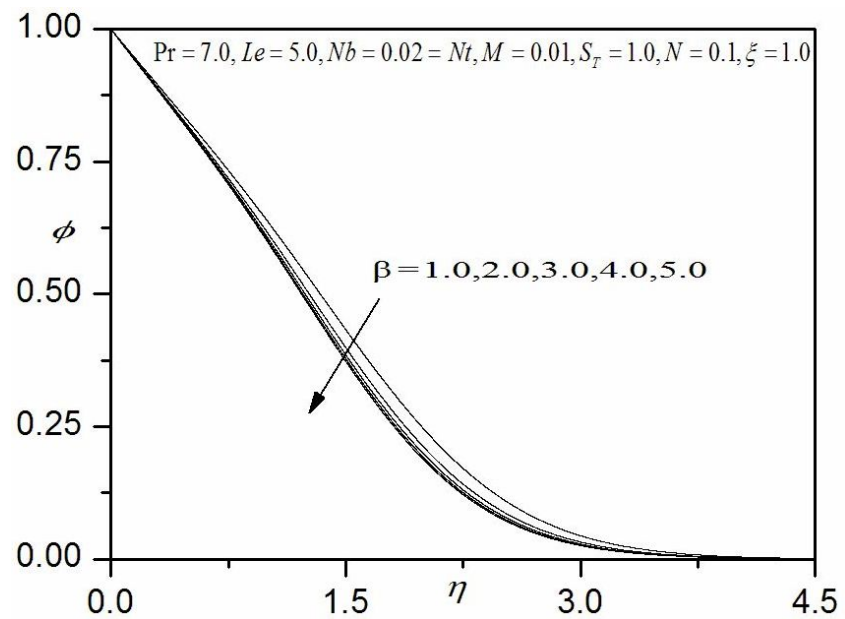

(c)

Fig. 3: Effect of $\beta$ on (a) velocity profiles, (b) temperature profiles, (c) concentration profiles

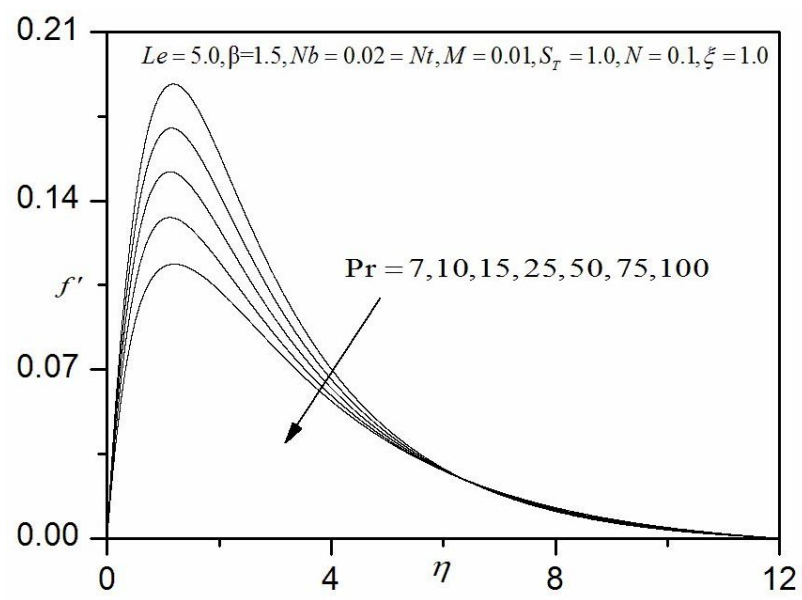

(a)

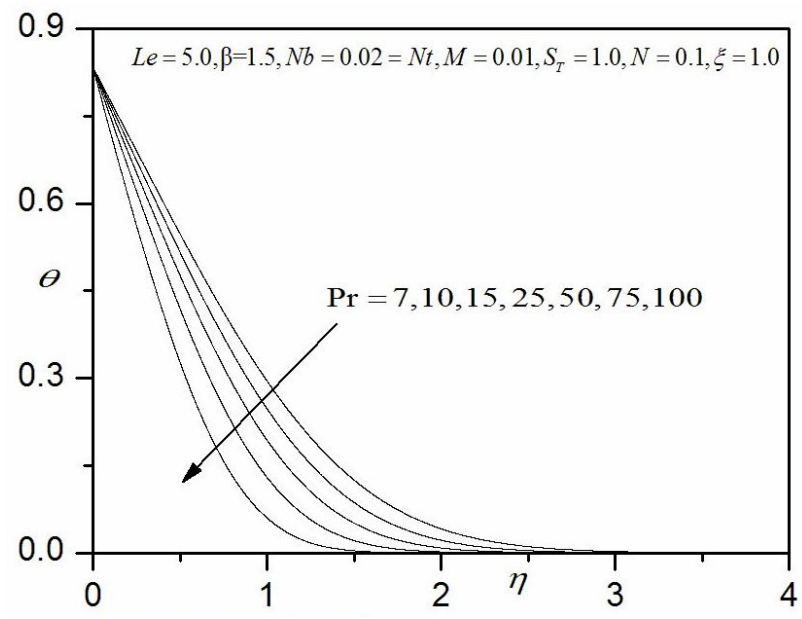

(b)

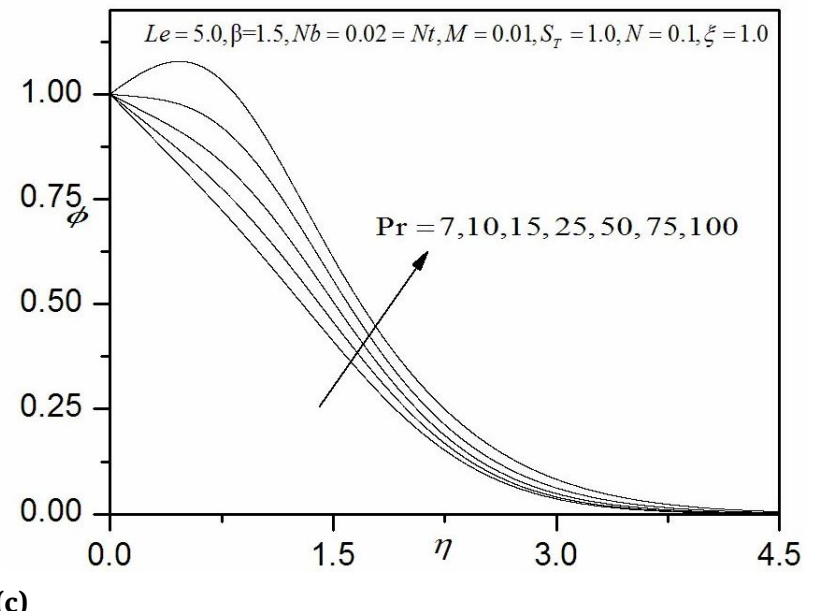

Fig. 4: Effect of Pr on (a) velocity profiles, (b) temperature profiles, (c) concentration profiles 


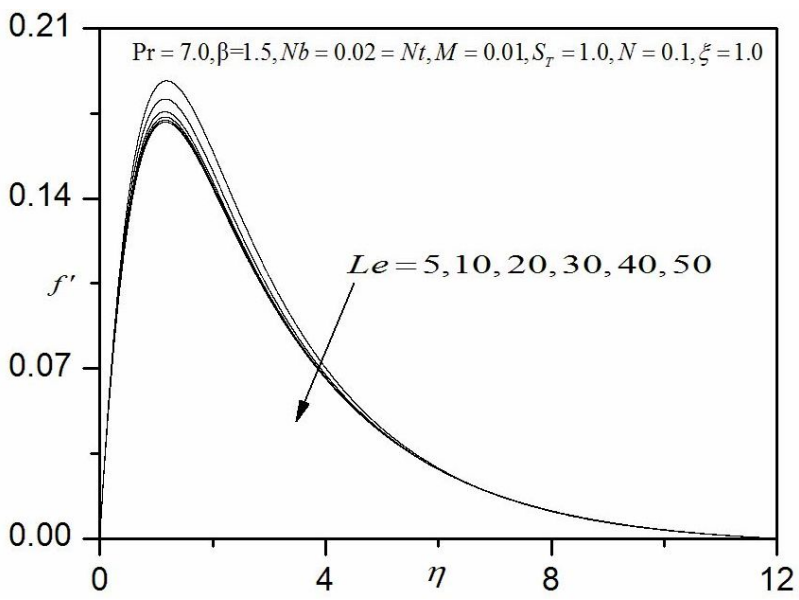

(a)

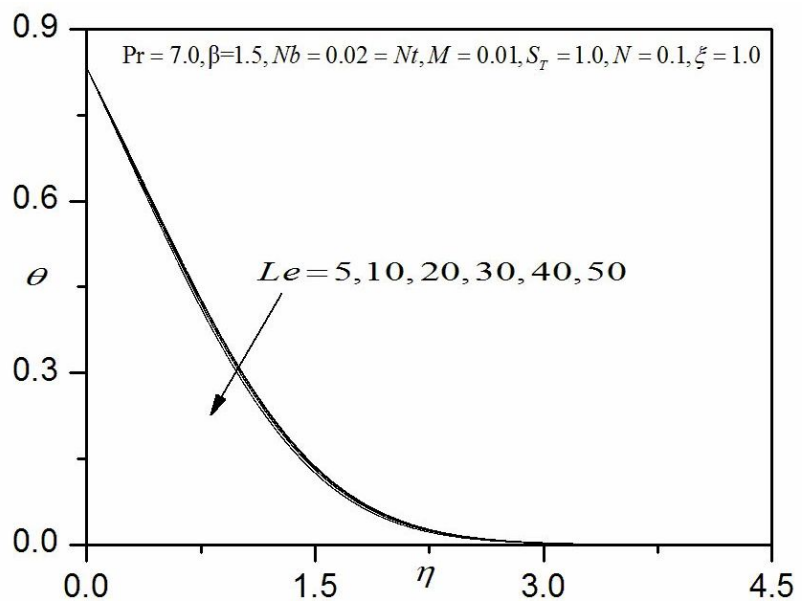

(b)

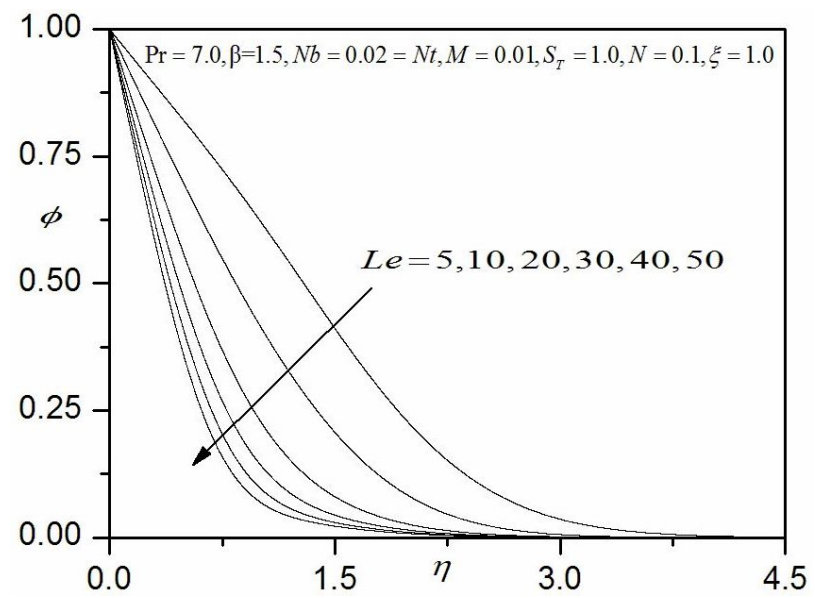

(c)

Fig. 5: Effect of Le on (a) velocity profiles, (b) temperature profiles, (c) concentration profiles

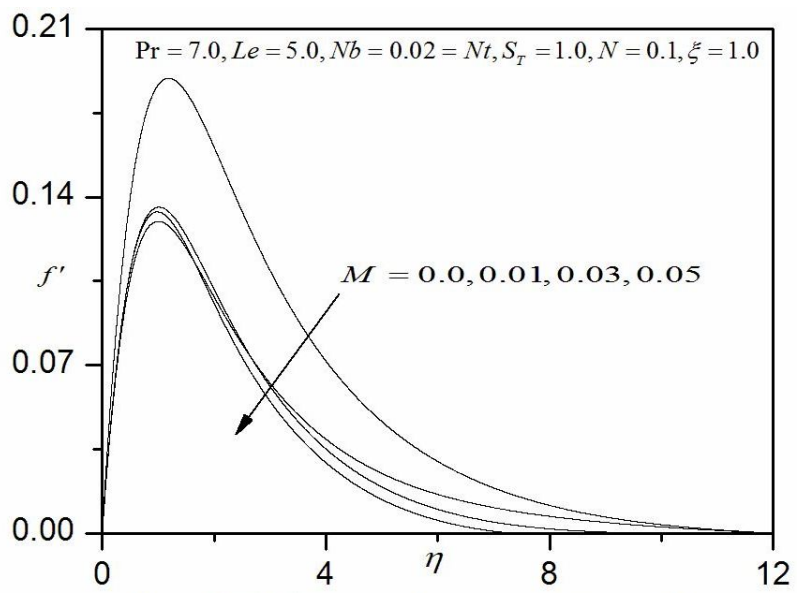

(a)

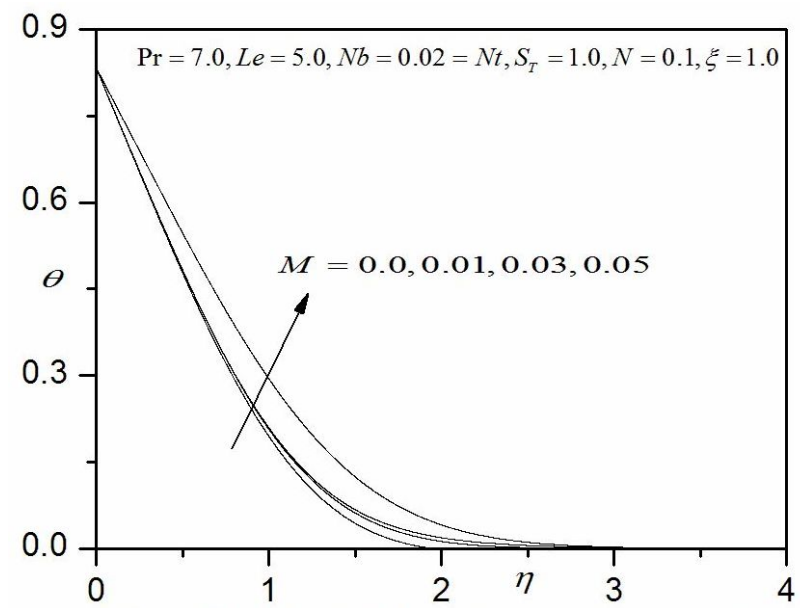

(b)

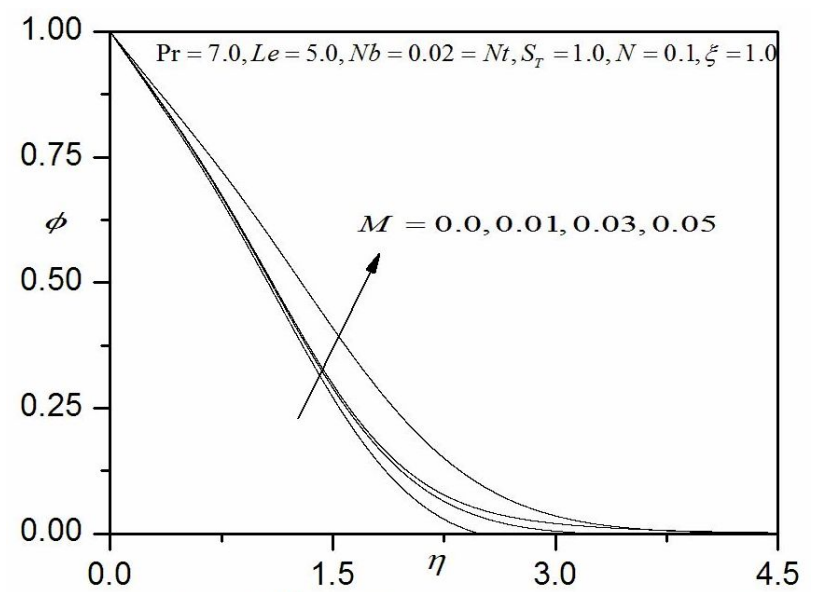

(c)

Fig. 6: Effect of $M$ on (a) velocity profiles, (b) temperature profiles, (c) concentration profiles 
conductivity of the viscoplastic nanofluid. Higher thermal conductivity implies lower Prandtl number and vice versa. With greater Prandtl number, thermal conductivity is reduces and this inhibits thermal conduction heat transfer which cools the boundary layer.

The monotonic decays in Fig. 4(b) are also characteristic of the temperature distribution in curved surface boundary layer flows. Inspection of Fig. 4(c) reveals that increasing Prandtl number strongly elevates the nano-particle concentration magnitudes. Infact a concentration overshoot is induced near the sphere surface. Therefore while thermal transport is reduced with greater Prandtl number, species diffusion is encouraged and nano-particle concentration boundary layer thickness grows.

Figs. 5(a-c) illustrate the evolution of velocity, temperature and concentration functions with a variation in the Lewis number, is depicted. Lewis number is the ratio of thermal diffusivity to mass (nano-particle) species diffusivity. $L e=1$ which physically implies that thermal diffusivity of the nanofluid and species diffusivity of the nanoparticles are the same and both boundary layer thicknesses are equivalent. For Le $<1$, mass diffusivity exceeds thermal diffusivity and vice versa for Le $>1$. Both cases are examined in Figs. 5(a-c). In Fig. 5(a), a consistently weak decrease in velocity accompanies an increase in Lewis number. Momentum boundary layer thickness is therefore increased with greater Lewis number. This is sustained throughout the boundary layer. Fig. 5(b) shows that increasing Lewis number also depresses the temperature magnitudes and therefore reduces thermal boundary layer thickness. Therefore judicious selection of nano-particles during doping of polymers has a pronounced influence on velocity (momentum) and thermal characteristics in enrobing flow, since mass diffusivity is dependent on the nature of nano-particle species in the base fluid. Fig. 5(c) demonstrates that a more dramatic depression in nanoparticle concentration results from an increase in Lewis number over the same range as Figs. 5(a, b). The concentration profile evolves from approximately linear decay to strongly parabolic decay with increment in Lewis number.

Figs. 6(a-c) exhibit the profiles for velocity, temperature and concentration, respectively with increasing magnetic body force parameter, $M . M=\frac{\sigma B_{0}^{2} a^{2}}{y \rho G r^{1 / 2}}$ defines the relative influence of magnetic Lorentzian drag force to viscous hydrodynamic force in the flow. With $\mathrm{M}<1$ viscous force dominates the magnetic force and the magnetohydrodynamic effect is weak. However Fig. 6(a) shows that even a weak increase in $M$ induces a marked deceleration in the boundary layer flow and simultaneously thickens

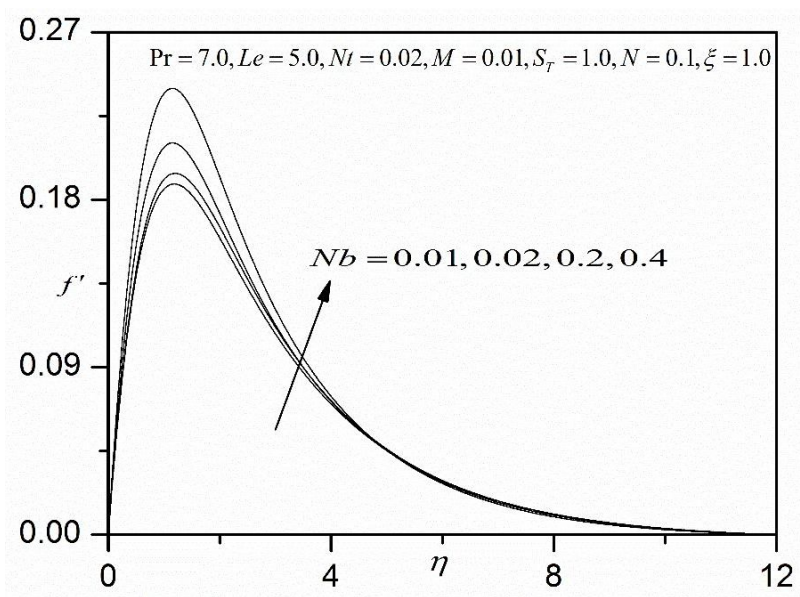

(a)

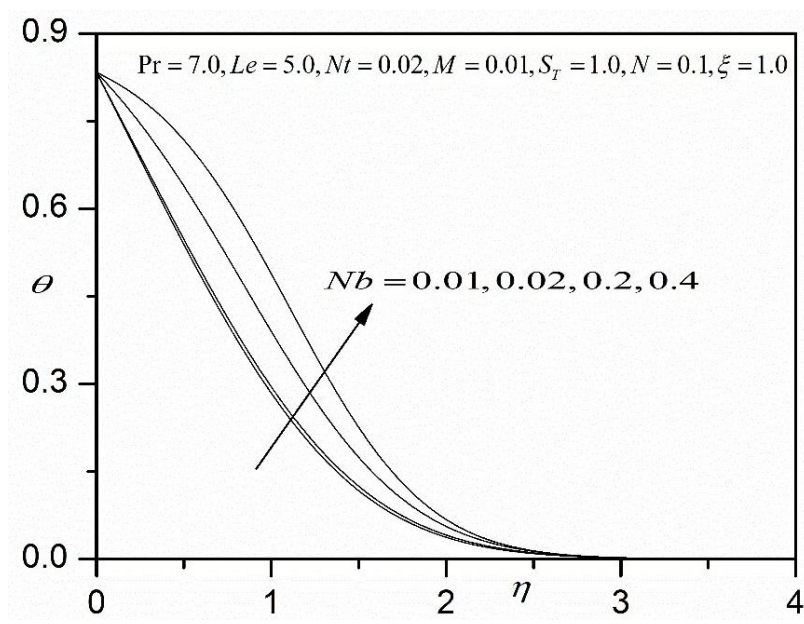

(b)

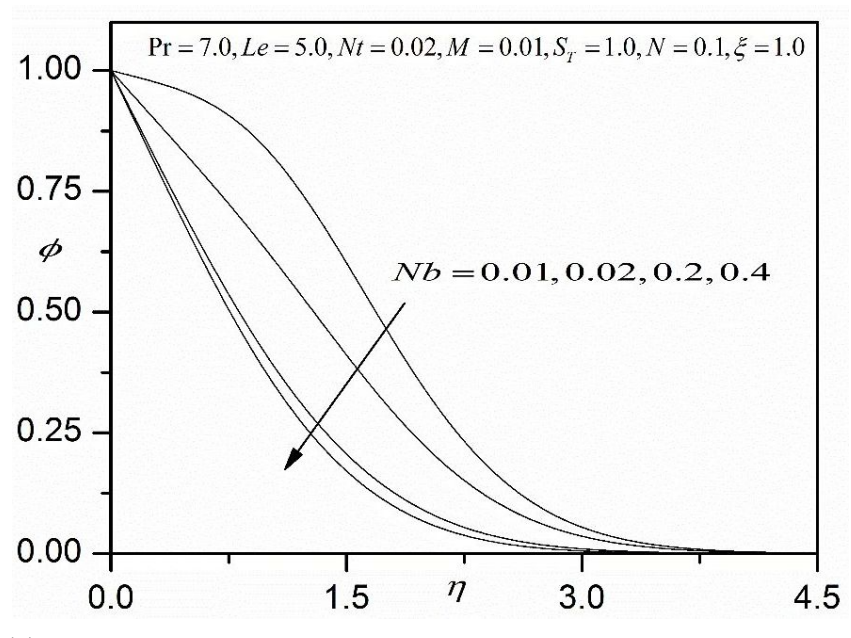

(c)

Fig. 7: Effect of $\mathrm{Nb}$ on (a) velocity profiles, (b) temperature profiles, (c) concentration profiles 


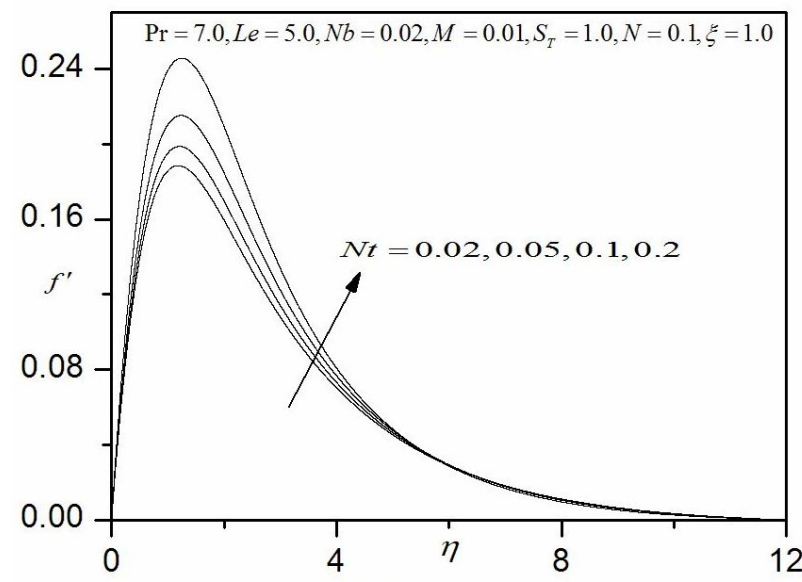

(a)

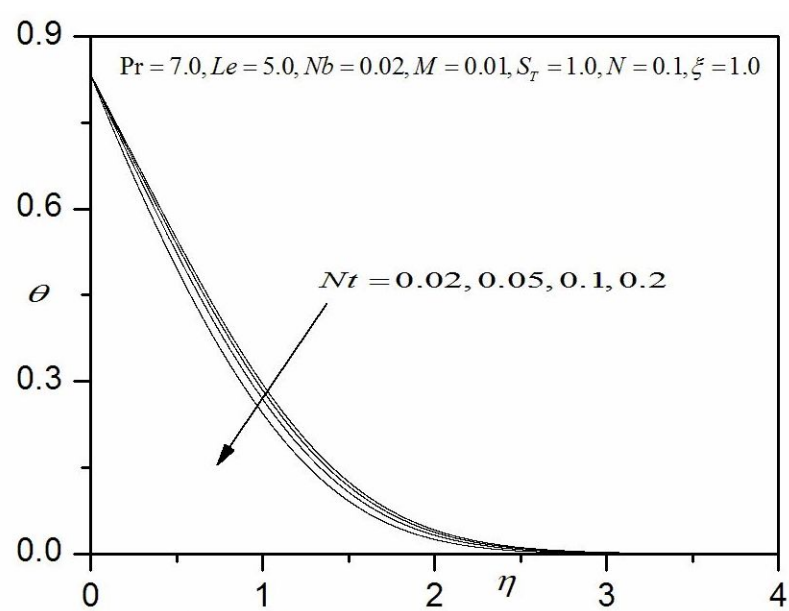

(b)

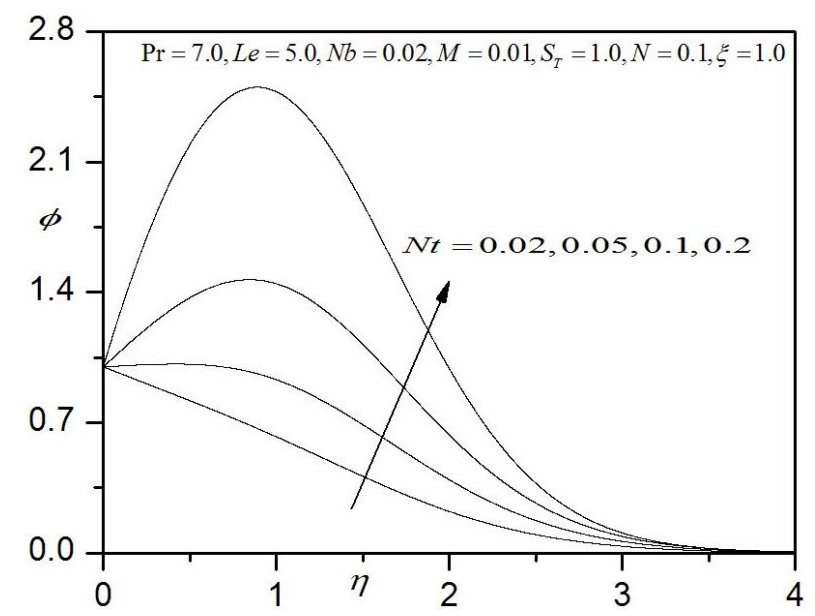

(c)

Fig. 8: Effect of Nt on (a) velocity profiles, (b) temperature profiles, (c) concentration profiles

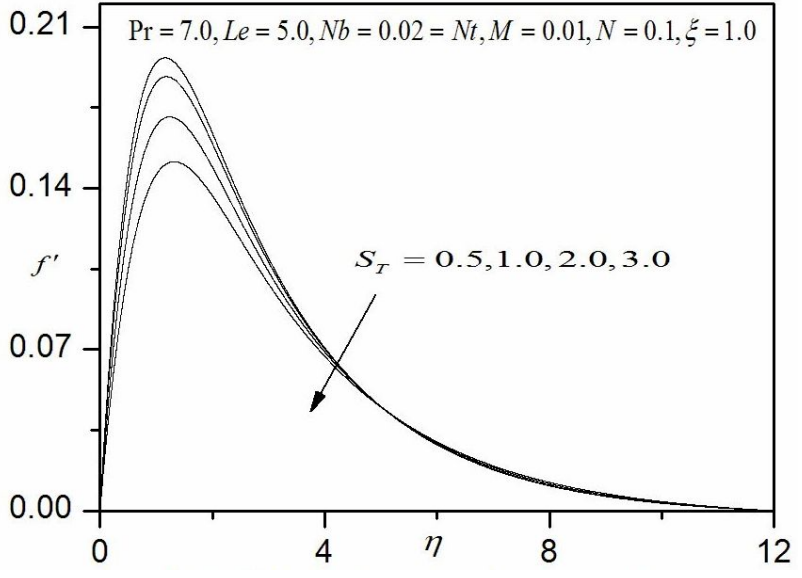

(a)

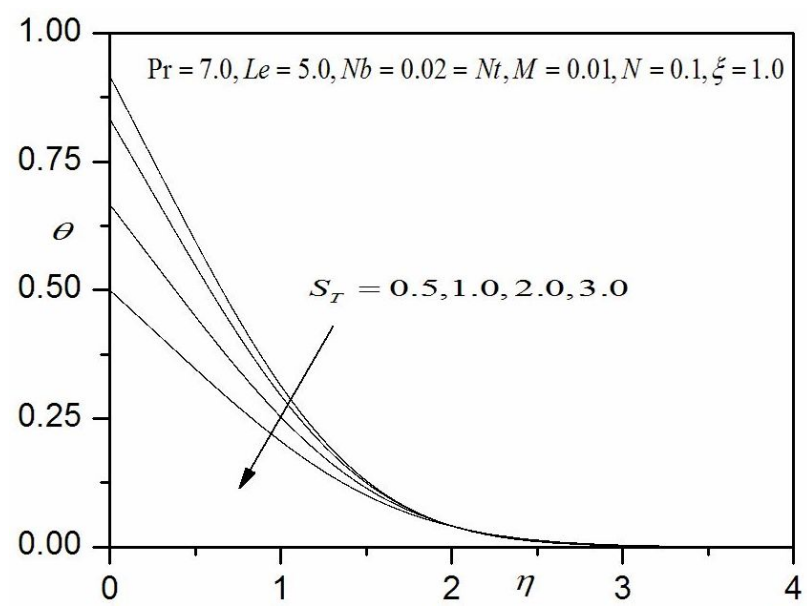

(b)

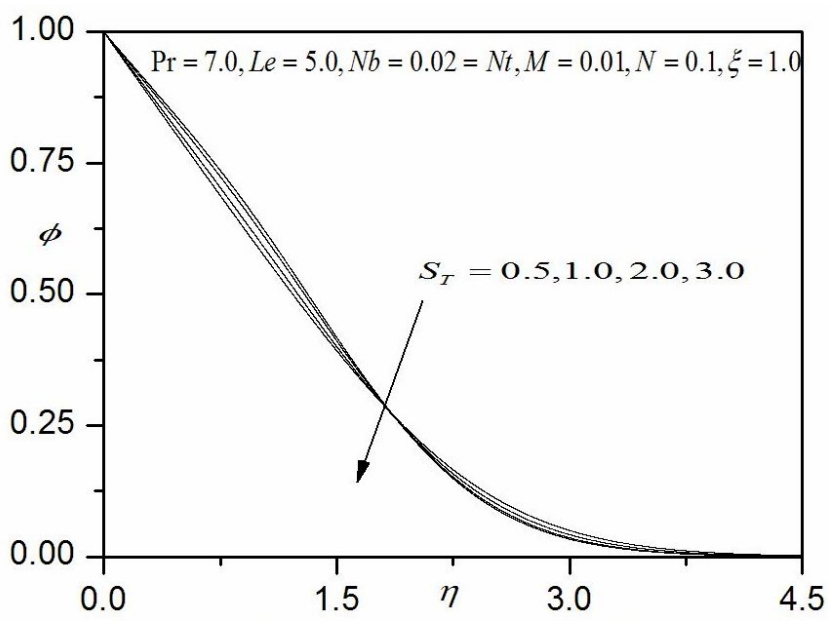

(c)

Fig. 9: Effect of $S_{T}$ on (a) velocity profiles, (b) temperature profiles, (c) concentration profiles 
the momentum boundary layer. Reverse flow or separation is never induced as testified to by the consistently positive values of velocity everywhere transverse to the sphere surface. This concurs with many other studies of magnetized nanofluid convection since the radial magnetic field acts to generate a perpendicular drag force which acts to decelerate the flow. Figs. 6(b) and 6(c) indicate that the dominant effect of greater magnetic parameter is to elevate both temperatures and nano-particle concentrations. The supplementary work expended in dragging the viscoplastic nanofluid against the action of the magnetic field manifests in kinetic energy dissipation. This energizes the boundary layer since the kinetic energy is dissipated as thermal energy, and this further serves to agitate improved species diffusion. As a result both thermal and nano-particle (species) concentration boundary layer thicknesses are increased.

Figs. 7(a-c) depict the response in velocity $\left(f^{\prime}\right)$, temperature $(\theta)$ and concentration $(\phi)$ functions to a variation in the Brownian motion parameter $(\mathrm{Nb})$. Increasing Brownian motion parameter physically correlates with smaller nanoparticle diameters. Smaller values of $\mathrm{Nb}$ corresponding to larger nanoparticles, and imply that surface area is reduced which in turn decreases thermal conduction heat transfer to the sphere surface. This coupled with enhanced macro-convection within the nanofluid energizes the boundary layer and accelerates the flow as observed in Fig. 7(a). Similarly the energization of the boundary layer elevates thermal energy which increases temperature in the viscoplastic nanofluid. Fig. 7(c) however indicates that the contrary response is computed in the nanoparticle concentration field. With greater Brownian motion number species diffusion is suppressed. Effectively therefore momentum and nanoparticle concentration boundary layer thickness is decreased whereas thermal boundary layer thickness is increased with higher Brownian motion parameter values.

Figs. $8(\mathrm{a}-\mathrm{c})$ illustrates the effect of the thermophoresis parameter $(N t)$ on the velocity $\left(f^{\prime}\right)$, temperature $(\theta)$ and concentration $(\phi)$ distributions, respectively. Thermophoretic migration of nano-particles results in exacerbated transfer of heat from the nanofluid regime to the sphere surface. This de-energizes the boundary layer and inhibits simultaneously the diffusion of momentum, manifesting in a reduction in velocity i.e. retardation in the boundary layer flow and increasing momentum (hydrodynamic) boundary layer thickness, as computed in Fig. 8(a). Temperature is similarly decreased with greater thermophoresis parameter (Fig. 8(b)). Conversely there is a substantial enhancement in nano-particle concentration (and species boundary layer thickness) with greater $N t$ val-

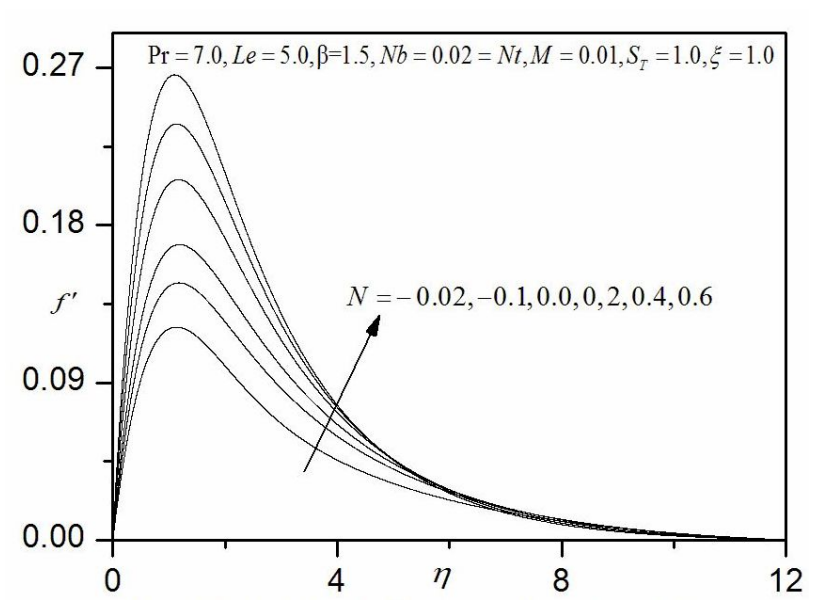

(a)

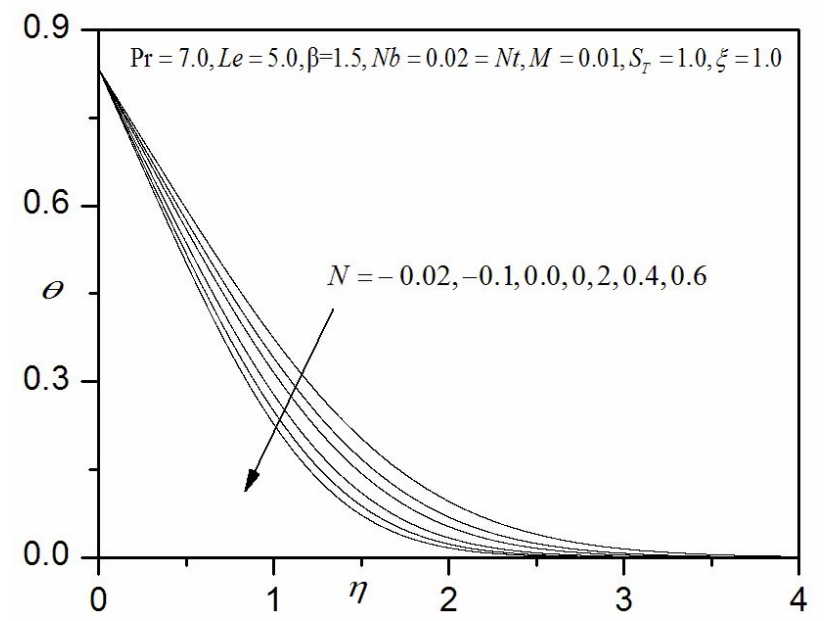

(b)

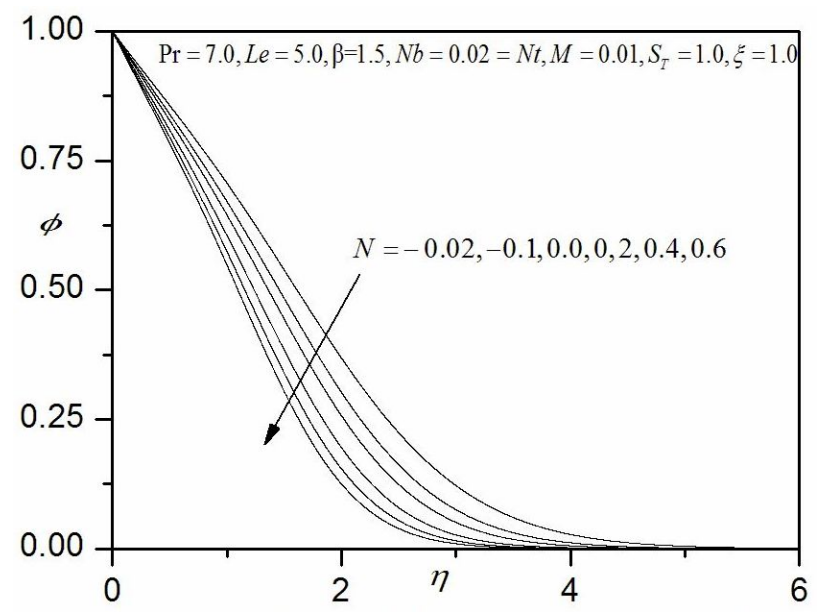

(c)

Fig. 10: Effect of $\mathrm{N}$ on (a) velocity profiles, (b) temperature profiles, (c) concentration profiles 


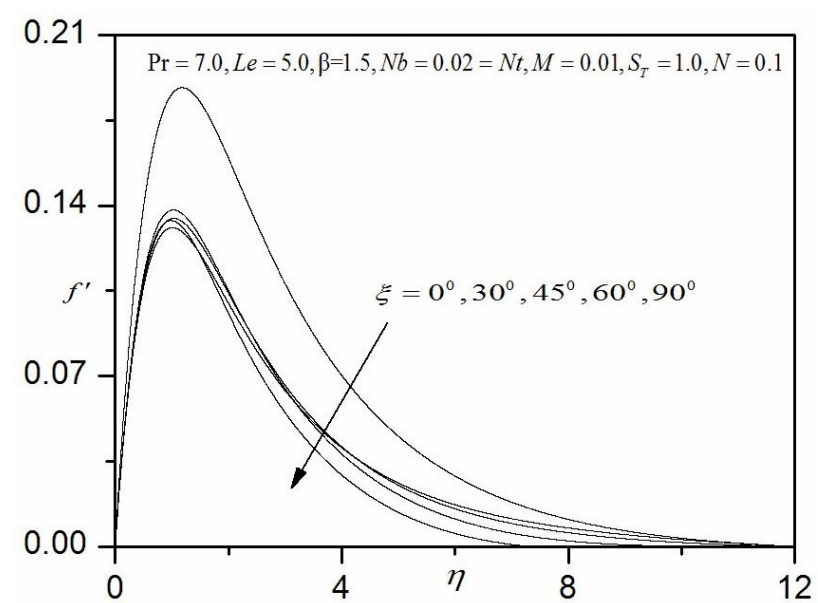

(a)

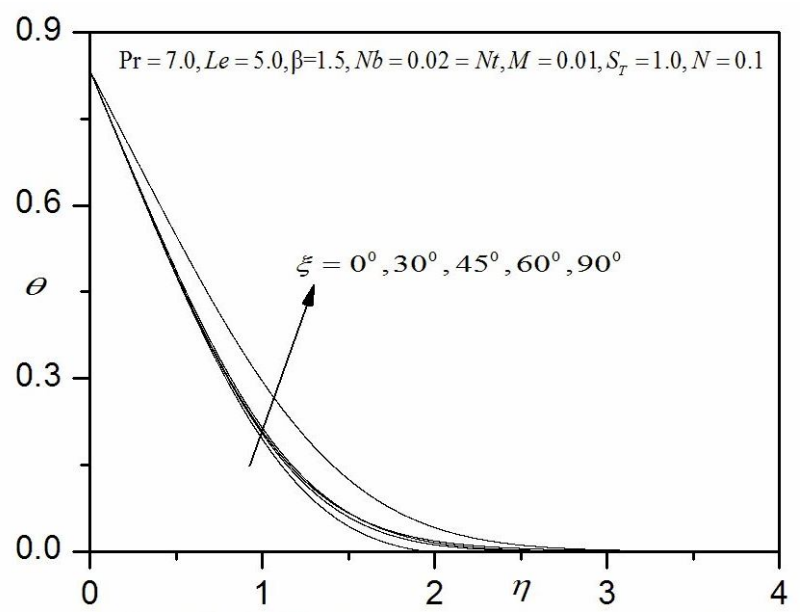

(b)

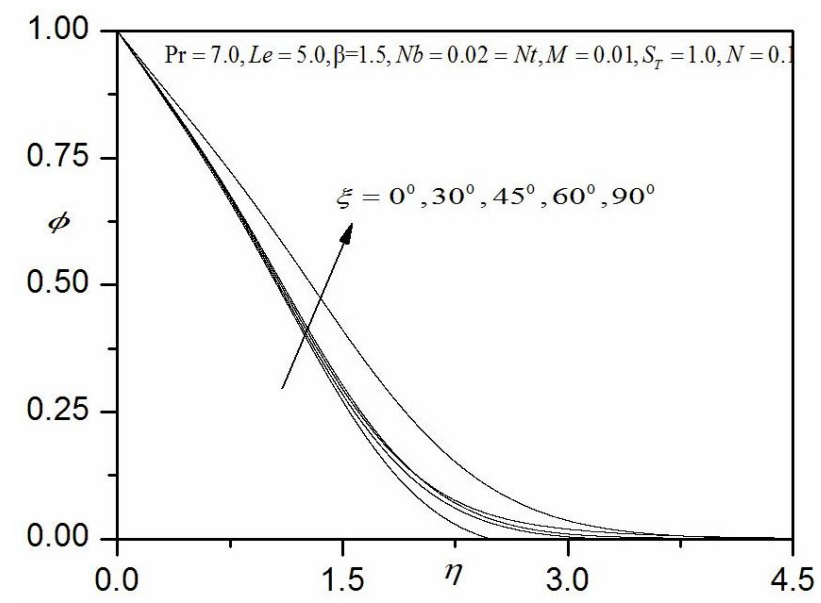

(c)

Fig. 11: Effect of $\xi$ on (a) velocity profiles, (b) temperature profiles, (c) concentration profiles ues. Similar observations have been made by Kunetsov and Nield [14] and Ferdows et al. [19] for respectively, both non-conducting Newtonian and electrically-conducting Newtonian flows.

Figs. 9(a-c) illustrate the variation of velocity, temperature and nano-particle concentration with transverse coordinate $(\eta)$, for different values of thermal slip parameter $\left(S_{T}\right)$. Thermal slip is imposed in the augmented wall boundary condition in eqn. (11). With increasing thermal slip less heat is transmitted to the fluid and this deenergizes the boundary layer. This also leads to a general deceleration as observed in Fig. 9(a) and also to a more pronounced depletion in temperatures in Fig. 9(b), in particular near the wall. The effect of thermal slip is progressively reduced with further distance from the wall (curved surface) into the boundary layer and vanishes some distance before the free stream. It is also apparent from Fig. 9(c) that nanoparticle concentration is reduced with greater thermal slip effect. Momentum boundary layer thickness is therefore increased whereas thermal and species boundary layer thickness are depressed. Evidently the non-trivial responses computed in figs. 9a-c further emphasize the need to incorporate thermal slip effects in realistic nanofluid enrobing flows.

Figs. 10 $(\mathrm{a}-\mathrm{c})$ present the effects of the buoyancy ratio $\mathrm{N}$ on the velocity, temperature and nano-particle concentration profiles. In general, increases in the value of $\mathrm{N}$ have the prevalent to cause more induced flow along the cone surface. This behavior in the flow velocity increases in the fluid temperature and volume fraction species as well as slight decreased in the thermal and species boundary layers thickness as $\mathrm{N}$ increases.

Figs. $11(\mathrm{a}-\mathrm{c})$ present the distributions for velocity, temperature and concentration fields with stream wise coordinate $\xi$, for the viscoplastic nanofluid flow. Increasing $\xi$ values correspond to progression around the periphery of the sphere, from the leading edge $(\xi=0)$. As $\xi$ increases, there is a weak deceleration in the flow (Fig. 11(a)), which is strongest nearer the sphere surface and decays with distance into the free stream. Conversely there is a weak elevation in temperatures (Fig. 11(b)) and nano-particle concentration magnitudes (Fig. 11(c)) with increasing stream wise coordinate.

Acknowledgement: The authors are grateful to the reviewers for giving their constructive comments for improving this article. The corresponding author is thankful to the management of Madanapalle Institute of Technology \& Science, Madanapalle for providing research facilities in the campus. 


\section{Conclusions}

A theoretical study has been conducted to simulate the magnetohydrodynamics viscoplastic nanofluid boundary layer flow in enrobing processes from an isothermal sphere with thermal slip using the Buongiorno formulation. The transformed momentum, heat and species boundary layer equations have been solved computationally with Keller's finite difference method. The present study has shown that:

1. Increasing viscoplastic (Casson) parameter decelerates the flow and also decreases thermal and nanoparticle concentration boundary layer thickness.

2. Increasing Prandtl number retards the flow and also decreases temperatures and nano-particle concentration values.

3. Increasing stream wise coordinate decelerates the flow whereas it enhances temperatures and species (nano-particle) concentrations.

4. Increasing thermal slip strongly reduces velocities, temperatures and nano-particle concentrations.

5. Increasing Brownian motion accelerates the flow and enhances temperatures whereas it reduces nanoparticle concentration boundary layer thickness.

6. Increasing thermophoretic parameter increasing momentum (hydrodynamic) boundary layer thickness and nanoparticle boundary layer thickness whereas it reduces thermal boundary layer thickness.

7. Increasing magnetohydrodynamic body force parameter decelerates the flow whereas it enhances temperature and nano-particle (species) concentrations.

The current study has explored an interesting viscoplastic model for electro-conductive nano materials which are currently of interest in aerospace coating applications. Time-dependent effects have been neglected. Future studies will therefore address transient enrobing viscoplastic nanofluid transport phenomena for alternative geometries (wedges, cones, Cylinder, Plates), also of interest in aerospace materials fabrication and will be communicated imminently.

\section{Nomenclature}

a Radius of the sphere (m)

$\mathrm{B}_{0}$ constant magnetic field (Tesla) $\mathrm{c}_{p}$ specific heat at constant pressure $(\mathrm{J} / \mathrm{kg} \mathrm{K})$

$\mathrm{C}$ dimensional concentration

$\mathrm{C}_{f}$ skin friction coefficient

$\mathrm{D}_{B}$ Brownian diffusion coefficient $\left(\mathrm{m}^{2} / \mathrm{s}\right)$

$\mathrm{D}_{T}$ thermophoretic diffusion coefficient $\left(\mathrm{m}^{2} / \mathrm{s}\right)$

f non-dimensional stream function

$\mathrm{g}$ acceleration due to gravity

Le Lewis number $\left(\mathrm{m}^{2} / \mathrm{s}\right)$

$M$ magnetic field parameter

$\mathrm{Nb}$ Brownian motion parameter

Nt thermophoresis parameter

$\mathrm{Nu}$ ocal Nusselt number

Sh Sherwood number

Pr Prandtl number

$\mathrm{S}_{T}$ thermal slip (jump) parameter

$\mathrm{T}$ temperature

$\mathrm{u}, \mathrm{v}$ non-dimensional velocity components along the $\mathrm{x}$ and y-directions, respectively

$\mathrm{x}$ stream wise coordinate

$\mathrm{y}$ transverse coordinate

\section{Greek symbols}

$\alpha$ thermal diffusivity

$\beta$ non-Newtonian Casson parameter

$\eta$ dimensionless transverse coordinate

$v$ kinematic viscosity $\left(\mathrm{m}^{2} / \mathrm{s}\right)$

$\theta$ non-dimensional temperature

$\rho$ density of nanofluid $\left(\mathrm{kg} / \mathrm{m}^{3}\right)$

$\sigma$ electrical conductivity of nanofluid (Siemens/meter)

$\xi$ dimensionless steam wise coordinate

$\psi$ dimensionless stream function

\section{Subscripts}

$\mathrm{w}$ conditions on the wall

$\infty$ free stream conditions

\section{References}

[1] Kleinstreuer C., Feng Y., Experimental and theoretical studies of nanofluid thermal conductivity enhancement: a review, Nano scale Research Letters. 2011, 6, 229.

[2] Wong K.V., Deleon O., Applications of nanofluid-current and future, Advances in Mechanical Engineering. 2010, 2, 519659.

[3] Sharma A., Tyagi V.V., Chen C.R., Buddhi D., Review on thermal energy storage with phase change materials and applications, Renewable and Sustainable Energy Reviews. 2009, 13, 318345

[4] Choi, S.U.S., Eastman, J.A., Enhancing thermal conductivity of fluids with nanoparticles. Proc. 1995 ASME Int. Mech. 
Engineering Congr. Expo. San Francisco. 1995, USA, ASME, FED231/MD66 99-105.

[5] Buongiorno, J., Convective Transport in Nanofluids. ASME J. Heat Transf. 2006, 128, 240-250.

[6] Kuznetsov, A. V., Nield, D.A., Natural convective boundarylayer flow of a nanofluid past a vertical plate: A revised model. Int. J. Therm. Sci. 2010, 49, 243-247.

[7] Abdul-Kahar, R., Kandasamy, R., Muhaimin, Scaling group transformation for boundarylayer flow of a nanofluid past a porous vertical stretching surface in the presence of chemical reaction with heat radiation. Comput. Fluids. 2011, 52, 15-21.

[8] Turkyilmazoglu, M., Exact analytical solutions for heat and mass transfer of MHD slip flow in nanofluids. Chem. Eng. Sci. 2012, 84, 182-187.

[9] Shit, G.C., Haldar, R., Ghosh, S.K., Convective heat transfer and $\mathrm{mhd}$ viscoelastic nanofluid flow induced by a stretching sheet. Int. J. Appl. Comput. Math. 2015, 4, 593-608.

[10] Shehzad, S.A., Hayat, T., Asghar, S., Alsaedi, A., Stagnation point flow of thixotropic fluid over a stretching sheet with mass transfer and chemical reaction. J. Appl. Fluid Mech. 2015, 8, 465-471.

[11] Casson, N., A flow equation for pigment-oil suspensions of the printing ink type. Mill, C.C., Ed., Rheol. Disperse Syst. Pergamon Press. Oxford, 1959, 84-104.

[12] Abdul Hakeem, A.K., Renuka, P., Vishnu Ganesh, N., Kalaivanan, R., Ganga, B., Influence of inclined Lorentz forces on boundary layer flow of Casson fluid over an impermeable stretching sheet with heat transfer. J. Magn. Magn. Mater. 2016, 401, 354-361.

[13] Nadeem, S., Mehmood, R., Akbar, N.S., Optimized analytical solution for oblique flow of a Casson nanofluid with convective boundary conditions. Int. J. Therm. Sci. 2014, 78, 90-100.

[14] Imtiaz, M., Hayat, T., Alsaedi, A., Mixed convection flow of Casson nanofluid over a stretching cylinder with convective boundary conditions. Adv. Powder Technol. 2016, 27, 22452256.

[15] Iqbal, Z., Mehmood, R., Azhar, E., Mehmood, Z., Impact of inclined magnetic field on micropolar Casson fluid using Keller box algorithm. Eur. Phys. J. Plus. 2017, 4, 1-13.

[16] Mehmood, Z., Mehmood, R., Iqbal, Z., Numerical Investigation of Micropolar Casson Fluid over a Stretching Sheet with Internal Heating. Commun. Theor. Phys. 2017, 67, 443.

[17] Nkurikiyimfura I., Wang Y., Pan Z., Heat transfer enhancement by magnetic nanofluids-A review, Renewable and Sustainable Energy Reviews. 2013, 21, 548-561.

[18] Ganguly R., Puri I.K., Field-assisted self-assembly of superparamagnetic nanoparticles for biomedical, MEMS and BioMEMS applications, H. Aref, Giessen EVD (Eds.), Advances in Applied Mechanics, Elsevier, USA, 2007, 41, 293-335.

[19] Akbar N., TripathiD., Bég O.A., Modelling nanoparticle geometry effects on peristaltic pumping of medical magnetohydrodynamic nanofluid with heat transfer, J. Mechanics in Medicine and Biology. 2016, 16(6), 20 pages.

[20] Qing J., Bhatti M.M., Abbas M.A., Rashidi M.M., Mohamed E., Sayed A., Entropy generation on MHD Casson nanofluid flow over a porous stretching/shrinking surface, Entropy. 2016, 8, 123.

[21] Janicki, M., Torzewicz, T., Kulesza, Z., Napieralski, A., “Active control of boundary conditions for dynamic thermal characterization of electronic components", Microelectronics Journal.
2013, 44, 1019-1024.

[22] Gao, N., Sun, H., Ewing, D., "Heat transfer to impinging round jets with triangular tabs”, Int J Heat Mass Transf., 2003, 46(14), 2557-2569.

[23] Popiel, C.O., Boguslawski, L., "Effect of flow structure on the heat or mass transfer on a flat plate in impinging round jet", In: 2nd UK national conference on heat transfer, 1998.

[24] Zaman K.B.M.Q., Reeder, M.F., Samimy, M., "Control of axisymmetric jet using vortex generators”, Phys Fluids. 1994, 6(2), 778-793.

[25] Gutmark, E.J., Grinstein, F.F., "Flow control with noncircular jets”, Ann Rev Fluid Mech. 1999, 31, 239-272.

[26] Soomro, F.A., Haq, R., Khan, Z.H., Zhang, Q., "Passive control of nanoparticle due to convective heat transfer of Prandtl fluid model at the stretching surface", Chinese Journal of Physics. 2017.

[27] Nadeem, S., Masood, S., Mehmood, R., Sadiq, M.A., “Optimal and Numerical Solutions for an MHD Micropolar Nanofluid between Rotating Horizontal Parallel Plates”, PLoS ONE. 2015, 10(6) e0124016.

[28] Nadeem, S., Mehmood, R., Masood, S., "Effects of transverse magnetic field on a Rotating Micropolar fluid between parallel plates with heat transfer", J. Mag. Mag. Mat. 2016, 401, 10061014.

[29] Nadeem, S., Mehmood, R., Motsa, S.S., “Numerical investigation on MHD oblique flow of Walter's B type nanofluid over a convective surface”, Int. J. Therm. Sci. 2015, 92, 162-172.

[30] Rana, S., Mehmood, R., Akbar, N.S., “Mixed convective oblique flow of a Casson fluid with partial slip, internal heating and homogeneous-heterogeneous reactions", J. Mol. Liq. 2016, 222, 1010-1019.

[31] Rana, S., Mehmood, R., Narayana, P.V.S., Akbar, N.S., “Free Convective Nonaligned Non-Newtonian Flow with Non-linear Thermal Radiation", Commun. Theor. Phys. 2016, 66(6), 687693.

[32] Mehmood, R., Nadeem, S., Saleem, S., Akbar, N.S., "Flow and heat transfer analysis of Jeffery nanofluid impinging obliquely over a stretched plate”, J. Tai. Inst. Chem. Eng. 2017, 74, 4958.

[33] Mehmood, R., Nadeem, S., Akbar, N.S., “Non-aligned ethylene-glycol $30 \%$ based stagnation point fluid over a stretching surface with hematite nano particles", J. Appl. Fluid Mech. 2016, 9(3), 1359-1366.

[34] Mehmood, R., Rana, S., Akbar, N.S., Nadeem, S., “Non-aligned stagnation point flow of radiating Casson fluid over a stretching surface”, Alex. Eng. J, 2017, Doi: 10.1016/j.aej.2017.01.010

[35] Nadeem, S., Mehmood, R., Akbar, N.S., “Oblique stagnation flow of Jeffery fluid over a stretching convective surface: Optimal Solution”, Int. J. Num. Meth. Heat \& Fluid Flow, 2015, 25(3), 454-471.

[36] Tabassum, R., Mehmood, R., Nadeem, S., “Impact of viscosity variation and micro rotation on oblique transport of Cu-water fluid", J. Coll. Inter. Sci. 2017, 501, 304-310.

[37] Mehmood, Z., Mehmood, R., Iqbal, Z., "Numerical Investigation of Micropolar Casson Fluid over a Stretching Sheet with Internal Heating", Commun. Theor. Phys. 2017, 67(4), 443448.

[38] V.R Prasad, S.A Gaffar, O.A Bég, Non-similar computational solutions for free convection boundary-layer flow of a nanofluid from an isothermal sphere in a non-Darcy porous medium, J. 
Nanofluids. 2015, 4, 1-11.

[39] Annasagaram Subba Rao, L. Nagaraja, M Sudhakar Reddy, M. Surya Narayana Reddy, Steady state transport phenomena on induced magnetic field modeling for a non-Newtonian Tangent Hyperbolic Fluid from an isothermal sphere with Soret and Dufour effects, Frontiers in Heat and Mass Transfer (FHMT). 2017, 9-17.

[40] G. Makanda, S. Shaw, P. Sibanda, Effects of radiation on MHD free convection of a Casson fluid from a horizontal circular cylinder with partial slip in non-Darcy porous medium with viscous dissipation, Boundary Value Problems. 2015, 75-84.

[41] O.A Bég, F. Mabood, I.M Nazru, Homotopy simulation of nonlinear unsteady rotating nanofluid flow from a spinning body, Int. J. Engineering Mathematics. 2015, Article ID 272079, 15 pages.

[42] Wouters, J. et al., Preparing polymer films doped with magnetic nanoparticles by spin-coating and melt-processing can induce an in-plane magnetic anisotropy, J. Appl. Phys. 2011, 109, 076105.

[43] Hussain T., Shehzad S.A., Alsaedi A., HayatT., Ramzan M., Flow of Casson nanofluid with viscous dissipation and convective conditions: A mathematical model, J. Cent. South Univ. 2015, 22, 1132-1140.

[44] Mitsoulis E., Sofou S., Calendering pseudoplastic and viscoplastic fluids with slip at the roll surface, ASME J. Appl. Mech. 2006, 73(2), 291-299.

[45] Casson N., Rheology of Disperse Systems, Ed. C.C. Mill, Pergamon Press, Oxford, 1959.

[46] Pham T.V., Mitsoulis E., Entry and exit flows of Casson fluids, Can. J. Chem. Eng. 1994, 72(6), 1080-1084.

[47] Keller H.B., A new difference method for parabolic problems, J. Bramble (Editor), Numerical Methods for Partial Differential Equations, Academic Press, New York, USA, 1970.

[48] Damseh R.A., Duwairi H.M., Al-Odat M., Similarity analysis of magnetic field and thermal radiation effects on forced convection flow, Turkish J. Eng. Env. Sci. 2006, 30, 83-89.

[49] Adhikari A., Sanyal D.C., Heat transfer on MHD viscous flow over a stretching sheet with prescribed heat flux, Bull. Int. Math. Virtual Inst. 2013, 3, 35-47.

[50] Eswara A.T., MHD Falkner-Skan boundary layer flow past a moving wedge with suction (injection), 19th Australasian Fluid Mechanics Conference Melbourne, Australia, 2014, 8-11.

[51] Malik M.Y., Salahuddin T., Hussain A., Bilal S., MHD flow of tangent hyperbolic fluid over a stretching cylinder: Using Keller box method, J. Magnetism Magnetic Materials. 2015, 395, 271-276.

[52] Bég O.A., Gaffar S.A., Prasad V.R., Uddin M.J., Computational solutions for non-isothermal, nonlinear magneto-convection in porous media with Hall/ionslip currents and Ohmic dissipation, Eng. Science Tech. 2016, 19(1), 377-394.

[53] Subba Rao A., Prasad V.R., Harshavalli K., Bég O.A., Thermal radiation effects on non-Newtonian fluid in a variable porosity regime with partial slip, J. Porous Media. 2016, 19(4), 313329.
[54] Subbarao, A, V.R Prasad, N. Nagendra, N.B Reddy and O.A Bég. Non-Similar Computational Solution for Boundary Layer Flows of Non-Newtonian Fluid from an Inclined Plate with Thermal Slip, J. of Appl. Fluid Mechanics. 2016, 9 (2), 795-807.

[55] Subbarao, A, N. Nagendra and V.R Prasad. Heat Transfer in a Non-Newtonian Jeffery's Fluid over a Non-Isothermal Wedge, Procedia Engineering. 2015, 127, 775-782.

[56] Subbarao, A, V.R Prasad, N.B Reddy and O.A Bég, Modelling laminar transport phenomena in a Casson rheological fluid from an isothermal sphere with partial slip, Thermal Science. 2015, 19(5), 1507-1519.

[57] Eid M.R., Mahny K.L., Flow and heat transfer in a porous medium saturated with a Sisko nanofluid over a nonlinearly stretching sheet with heat generation/absorption, Heat Transfer-Asian Res. 2018, 47, 54-71.

[58] Eid, M.R. and S.R. Mishra. Exothermically reacting of nonNewtonian fluid flow over a permeable non-linear stretching vertical surface with heat and mass fluxes. Comput. Thermal Sci.: Int. J., 2017, 9, 283-296.

[59] Rashad, A.M., Impact of Thermal Radiation on MHD Slip Flow of a Ferro fluid over a non- isothermal Wedge, Journal of Magnetism and Magnetic Materials. 2017, 422, 25-31. 